\section{Ankara Üniversitesi Eğitim Bilimleri Fakültesi Özel Eğitim Dergisi}

2022, 23(1), 191-218

\title{
Öğrenme Güçlüğü Olan Ortaokul Öğrencilerine Uygulanan Matematik Problemi Çözme Müdahaleleri: Kapsamlı Alanyazın İncelenmesi
}

\author{
Ufuk Özkubat 1
}

\author{
Alpaslan Karabulut ${ }_{2}$
}

Cihan Sert 3

\begin{abstract}
$\ddot{O} z$
Giriş: Öğrenme güçlüğü olan öğrencilere yönelik matematik problemi çözme müdahaleleri içeren çalışmaların incelenmesi, bu öğrencilere destek sağlayacak uygulamaların belirlenmesi için önemli görülmektedir. Ayrıca müdahale çalışmalarının yöntemsel olarak belirli kalite standartları çerçevesinde değerlendirilmesi, uygulamaların yinelenebilirliği ve sonuçların güvenirliği hakkında bilgi sağlamaktadır. Bu araştırmada, a) son 20 yılda, ortaokul düzeyinde bulunan öğrenme güçlüğü olan öğrencilere yönelik uygulanan matematik problemi çözme müdahalelerinin derlenmesi, b) bu araştırmaların özelliklerinin betimsel olarak listelenmesi ve c) bu araştırmaların kalite göstergeleri açısından incelenmesi amaçlanmaktadır.
\end{abstract}

Yöntem: Elektronik veri tabanları, dergi indeksleri ve araştırma referansları temel alınarak kapsamlı bir tarama gerçekleştirilmiştir. Katılımcı makalelerin bu araştırmaya dahil edilmesine ve dışlanmasına ilişkin bazı temel seçim ölçütleri doğrultusunda toplam 9 makale; betimsel analiz ve kalite göstergeleri bağlamında incelenmiştir. Araştırmaların; betimsel analizi yapılarak özellikleri ortaya konulmuş, tek denekli deneysel desenlerin kullanıldığı araştırmalar için belirlenen kalite göstergeleri doğrultusunda incelenerek kalite düzeyleri belirlenmiştir.

Bulgular: $\mathrm{Bu}$ araştırmada incelenen çalışmaların görsel grafiklerinin ve yazılı bulgularının incelenmesi sonucunda, çeşitli problem çözme öğretim müdahalelerinin (doğrudan öğretim, somut-yarı somut-soyut stratejisi, şema temelli yaklaşım, öz düzenleme stratejisi ve ipucu kartları, STAR stratejisi, açık anlatım, LAP stratejisi, görsel stratejiler, Solve It! ve SOLVE stratejisi) problem çözme becerilerinin kazanımında etkili olduğu belirlenmiştir. Çalışmalar kalite göstergeleri açısından genel olarak değerlendirildiğinde, temel kalite göstergelerinin başlama düzeyi, deneysel kontrol/iç geçerlik ve diş geçerlik bileşenlerinde tüm çalışmalar belirlenen ölçütleri karşılamaktadır. Diğer bileşenler için \%44 ile \%78 arasında değişen orandaki çalışmanın, belirlenen ölçütleri karşıladığı görülmüştür. Sadece bir çalışmanın kalite göstergelerinin tümünü karşıladığı görülmüştür.

Tartışma: Araştırma bulguları, ilgili alanyazın ve teorik görüşler çerçevesinde tartışılmıştır. Öğretmenlere, uygulamaya ve alanda çalışan araştırmacılara ileride yapılacak araştırmalara yönelik önerilerde bulunulmuştur. $\mathrm{Bu}$ doğrultuda, öğrenme güçlüğü olan öğrenciler ile çalışan uzmanların, problem çözme aşamaları, şematik düzenleyiciler, bilişsel ve üstbilişsel stratejiler ile sesli düşünme teknikleri gibi öğrencilerin başarılı bir şekilde problem çözümünü kolaylaştıracak stratejileri içeren müdahale programları oluşturması gerektiği belirtilmiştir.

Anahtar sözcükler: Öğrenme güçlüğü, matematik problemi çözme müdahaleleri, matematik öğretimi, betimsel analiz, kalite göstergeleri.

Atıf için: Özkubat, U., Karabulut, A., \& Sert, C. (2022). Öğrenme güçlüğü olan ortaokul öğrencilerine uygulanan matematik problemi çözme müdahaleleri: Kapsamlı alanyazın incelenmesi. Ankara Üniversitesi Eğitim Bilimleri Fakültesi Özel Eğitim Dergisi, $23(1), \quad 191-218$. https://doi.org/10.21565/ozelegitimdergisi.774650

\footnotetext{
${ }^{1}$ Sorumlu Yazar: Arș. Gör. Dr., Gazi Üniversitesi, E-posta: ufukozkubat@ @azi.edu.tr, https://orcid.org/0000-0002-9626-5112 ${ }^{2}$ Dr. Öğr. Üyesi, Bolu Abant İzzet Baysal Üniversitesi, E-posta: karabulut_a@ibu.edu.tr, https://orcid.org/0000-0002-7355$\underline{5109}$

소․ Gör., Gazi Üniversitesi, E-posta: cihan.sert@gazi.edu.tr, https://orcid.org/0000-0002-5602-1156
} 


\section{Giriş}

Temel akademik becerilerin kazandırılması amacıyla öğrencilere okul öncesi dönemden itibaren eğitim verilmektedir. Öğrencilerin hayatlarında başarıyı yakalayabilmeleri ve bağımsız olarak yaşamlarını sürdürebilmeleri için temel akademik becerileri kazanmaları gerekmektedir. Okuma, yazma, temel işlemler ve problem çözme öğrencilere kazandırılması gereken temel akademik becerilerin başında gelmektedir. Bir yetersizlik türü olan öğrenme güçlüğünde problem çözme, temel müdahale alanlarından biri olarak görülmektedir (Miller \& Mercer, 1997; Montegue, 1992). Matematik problemi çözme hem öğrenme güçlüğü olan öğrenciler hem de tipik gelişim gösteren öğrenciler için zor bir beceridir (Jonassen, 2003; Schurter, 2002). Bu gerekçeyle problem çözmede sorun yaşayan öğrenciler desteklenmelidir (Hutchinson, 1993). Öğrenme güçlüğü olan öğrencilerin desteklenmesi için farklı müdahale yöntemleri bulunmaktadır (Lee vd., 2020; Maccini \& Hughes, 1997; Maccini vd., 2007; Marita \& Hord, 2017; Myers vd., 2015). Bu müdahale yöntemlerinin bilinmesi ve müdahale uygulanan çalışmaların incelenmesi öğrenci ihtiyaçları doğrultusunda uygun yöntemin seçilebilmesi için önemlidir.

Öğrenme güçlüğü, yazılı ve sözlü dili anlama ve kullanmada temel olan bir veya daha fazla bilişsel sürecin etkilenmesiyle ortaya çıkan dinleme, düşünme, konuşma, okuma, yazma ve matematiksel hesap yapmada yaşanan güçlükler olarak tanımlanmaktadır (Fuchs vd., 2000; Hamilton \& Shinn, 2003; Stanford \& Oakland, 2000). Öğrenme güçlüğü olan öğrencilerin sayıları yazma, temel işlemleri yapma, işlemsel süreçleri ve detayları hatırlama, işlemleri doğru adımlarla gerçekleştirme ve matematik terimlerini ya da dilini kullanma ile ilgili yetersizlikleri, problem çözme süreçlerini etkilemektedir (Bryant vd., 2000; Geary, 2004; Guerin \& Male, 2006; Kingsdorf \& Krawec, 2014). Problem çözme sürecine ilişkin birçok tanım bulunmaktadır. Bu tanımların ortak noktaları birleştirildiğinde, problem çözme; birleştirme ve analiz etme becerilerini içeren (Cawley \& Miller, 1986), bir ve/veya daha fazla adımdan oluşan (Fuchs vd., 2004), çözüm sürecinde kullanılacak gerekli hesaplama işlemlerinin ayırt edilmesini gerektiren (Carpenter vd., 1993) bir süreç olarak tanımlanabilir. Problem çözme pratiği olan birçok öğrencinin problem çözme stratejileri doğal olarak gelişir (McGilly \& Siegler, 1989). Ancak bazı öğrencilerin yetersizlikleri, onların doğal olarak problem çözme stratejisi geliştirmesinde sınırlılık yaşamasına ve öğrencilerin okul performanslarının da düşmesine neden olur (Montague, 1997). Aynı zamanda öğrenme güçlügü olan öğrenciler matematiksel bilgileri transfer etme ve problemlerin kavramsallaştırılması konularında güçlükler yaşamaktadır (Rivera, 1997). Öğrenme güçlüğü olan öğrencilere yönelik uygulanan müdahaleler, problem çözme sürecinin öğretilmesi ve belirtilen sürecin nasıl uygulanması gerektiğini öğretmek yerine (Foegen, 2008; Maccini vd., 2007) temel işlem becerilerini öğretmeyi hedef almaktadır (Miller \& Hudson, 2007). Özellikle kendi öğrenme süreçlerini yönetmede ve bilişsel süreçlerinde sınırlılıkları olan öğrenciler için sadece problem çözme aşamalarını bilmek yeterli olmamaktadır. Dolayısıyla süreç temelli, düzenli ve stratejik bir eğitimle (Montague, 2007, 2008) öğrenme güçlüğü olan öğrencilere problem çözümü için planlamadan çözüme ulaşana kadar tüm süreçte yardımcı olacak uygun stratejiler öğretilmelidir (Jitendra \& Hoff, 1996; Özkubat vd., 2020). Bu öğrencilere matematik problemi çözmeyi öğretirken, sadece ne yapmaları gerektiği değil, bunu nasıl yapmaları gerektiği de öğretilmelidir (Goldman, 1989). Bu doğrultuda, alanyazında öğrencilerin matematik problemi çözme sürecinde bilişsel ve üstbilişsel stratejileri temel alarak işlemlerin öğretimine odaklanan süreç temelli öğretimlere yönelinmiştir (Hutchinson, 1993). Süreç temelli öğretimlerde temel olarak problem çözme aşamaları izlenmektedir. $\mathrm{Bu}$ aşamalarda bilişsel işlemleri gerçekleştirmek amaciyla uygun stratejilerin öğrencilere kazandırılması hedeflenmektedir. Bu bilişsel stratejilerle birlikte üstbilişsel işlemleri yönetmek amacıyla üstbilişsel stratejilerde süreç izlenmekte ve sorgulanmaktadır. Bu beceriler hem başarılı bir şekilde problem çözme becerileri için gereklidir hem de genel matematik başarısı ile yüksek düzeyde ilişkilidir (Bryant vd., 2000).

Alanyazında ortaokul düzeyindeki öğrenme güçlüğü olan öğrencilerin matematik problemleri çözme performanslarının geliştirilmesinde farklı müdahaleler kullanılmaktadır (Lee vd., 2020; Maccini \& Hughes, 1997; Maccini vd., 2007; Marita \& Hord, 2017; Myers vd., 2015). Bu müdahaleler, genel olarak doğrudan öğretim yöntemi aracılığıyle sunulan stratejiler, açık anlatım yöntemi, somut-yarı somut-soyut stratejisi, şema temelli strateji, öz düzenleme stratejisi ve hatırlatıcılar yardımıyla sunulan stratejiler şeklinde karşımıza çıkmaktadır. Belirtilen stratejiler incelendiğinde, Montague tarafından geliştirilen 'Bunu Çöz!' (Solve It!) öğretim stratejisi, öğrenme güçlüğü olan öğrencilerin matematik problem çözme performanslarını geliştirmek amacıyla desenlenmiştir. Montague (1992), başarılı bir şeklide problemi çözmek için gerekli olan yedi bilişsel stratejiyi tanımlamıştır (Read [Okuma], Paraphrase [Kendi cümleleri ile ifade etme], Visualize [Görselleştirme], Hypothesize [Hipotez oluşturma], Estimate [Tahmin etme], Compute [Hesaplama], Check [Kontrol etme]). Her bir bilişsel strateji için de kendine yönerge verme, kendine soru sorma ve kendini izleme stratejilerini (ör. Say [Söyle], Ask [Sor], Check [Kontrol et]) stratejisine yerleştirmiştir. Bu strateji sayesinde öğrenciler, problemi dikkatli bir şekilde okumayı, problemi kendi cümleleri ile ifade etmeyi, bilgileri analiz etmeyi, bu doğrultuda bir 
plan geliştirmeyi, problemi çözmeyi ve çözümlerini kontrol etmeyi öğrenmektedirler (Reid \& Lienamann, 2006). Somut-yarı somut-soyut yaklaşımı, aşamalandırılmış bir öğretim yaklaşımı olup sırasıyla somut, yarı somut ve soyut aşamalarını içermektedir (Marita \& Hord, 2017). İlk aşama olan somut aşamasında, problemin somut nesneler ile ifade edilerek çözümü amaçlanmaktadır. İkinci aşama olan yarı soyut aşamasında problem, resimler, çizimler ve iki boyutlu şekiller aracıllığılla görsel olarak temsil edilerek çözümü amaçlanmaktadır. Son aşama olan soyut aşamasında ise semboller ve eşitlikler kullanılarak problem matematik dili ile ifade edilerek çözümü gerçekleştirilmektedir (Strickland \& Maccini, 2013). Böylece problem içerisindeki verilerin görseller ile desteklenerek aşamalandırılmış şekilde çözülmeleri öğrenme güçlüğü olan öğrencilerin cebir, geometri, oran ve orantı konularında problem çözme performanslarını artırmaktadır (Hunt \& Vazquez, 2014; Scheuermann vd., 2009). Hatırlatıcı destekli stratejiler (LAP, READER, STAR, SOLVE vb.) bir veya daha fazla sözcüguün baş harflerinden veya ilk birkaç harfinden oluşturulmuş kelimelerdir (Reid \& Lienamann, 2006). Bu kelimelerin her bir harfi bir bilişsel strateji adımını işaret ederek matematik problemi çözümünde, problem çözme basamaklarını hatırlatmak amacıyla kullanılmaktadır. Örneğin STAR stratejisi, (Search the problem [Problemi incele], Translate the words into an equation in picture form [Problemi görselleştir], Answer the problem [Problemi cevapla], Review the solution [Çözümü kontrol et]) basamakları bulunan bir bilişsel strateji öğretimlerinden birisidir. Hatırlatıcı destekli stratejiler ile problemlerin çözümü; öğrenme güçlüğü olan öğrencilerin problemde verilen bilgileri analiz etmelerini, planlamalarını yaparak planı uygulamalarını ve problem çözme süreçlerini kontrol etmelerini sağlayarak doğru sonuca ulaşmalarını sağlamaktadır (Freeman-Green vd., 2015; Maccini \& Ruhl, 2000; Test \& Ellis, 2005). Şema temelli öğretim stratejisinde, problem türlerine uygun olarak geliştirilmiş şemalar kullanılmaktadır (Jitendra vd., 2002). Şemalar, problem içerisinde yer alan ilişkileri anlamlandırmak için kullanılan, soyut olan problemi yarı somut ya da somut bir şekle dönüştürmek için kullanılan araçlar olarak tanımlanmaktadır (Marshall, 1995). Bu araçlar, öğrenme güçlüğü olan öğrenciler problemi çözerken problemde geçen bilgiyi görselleştirme, verilenleri ve istenenleri organize etme amacıyla kullanılmaktadır. Şema temelli öğretim stratejisinin kullanılması, öğrencilerin problemlerin şemalara nasıl yerleştirilmesi gerektiğini ve problemleri çözerken doğru işlemi nasıl seçmesi gerektiğini anlamasına yardımcı olmaktadır (Jitendra vd., 2002). Öğrenme güçlüğü olan öğrencilerin matematik problemi çözme performanslarının geliştirilmesinde kullanılan müdahalelerin tümünde problemin görsel olarak temsil edilmesinin bir basamak olarak yer aldığı görülmektedir. Görselleştirme stratejisi kullanımı, problem çözme sürecinde güçlü bir problem temsil işlemi olarak betimlenmektedir (Van Garderen, 2007). Matematik alanında, görsel imge kullanımının, farklı problem türlerine ilişkin problemlerin çözümünde önemli bir değişken olabileceği savunulmaktadır (Ives, 2007). Görsel imge kullanımı, bir problemin anlaşılmasını sağlanmada, problem çözümü için seçilecek işlemleri belirlenmede ve bellekten bilgileri geri çağrılmada önemli rol oynamaktadır. Görselleştirmenin, matematik becerileri içerisinde yer alan akıl ve mantık yürütme işlemi için de kullanıldığı belirtilmektedir (Geary, 2004). Belirtilen yöntem ve stratejiler, problemin tanımlanmasını ve anlaşılmasını sağlamada, problemin çözümü için seçilecek işlemleri belirlemede, problem içinde verilen bilgileri kullanarak çözümü gerçekleştirmede, gerekli hesaplamaları doğru bir şekilde yapmada, çözüm basamakları için işlem sırasını takip etmede, akıcılık sağlamada, bellekten bilgileri geri çağırmada, problemin çözüm aşamalarını hatırlamada önemli rol oynamaktadır. Dolayısıyla öğrencilere problem çözme yöntem ve stratejilerinin öğretimi, birçok kolaylık sağlamakta ve sonuçların doğruluğunu arttırmaktadır (Bottge \& Cho, 2013; Bottge vd., 2014; Hunt \& Vazquez, 2014; Scheuermann vd., 2009; Strickland \& Maccini, 2013).

Tek denekli araştırmalardaki uygulamanın kalite düzeyini ve yöntemsel olarak yapılması gereken işlemlerin uygunluğunu değerlendirmek önemlidir. Bu değerlendirmeyi yapabilmek için belirlenmiş nesnel ölçütlerinin olması gerekir. Bu sayede bir araştırmanın kalite düzeyi olarak kabul edilebilir en düşük seviyeyi karşılayışı ölçülebilir (Horner vd., 2005). Yüksek kaliteli bir araştırmayı gösteren öğelere kalite göstergeleri denilmektedir (Cook vd., 2019). Alanyazında tek denekli araştırmaların yöntemsel olarak uygunluğunu ölçmek için yapılmış çalışmalar mevcuttur (Busk \& Serlin, 1992; Kratochwill \& Stoiber, 2002). Bu çalışmalara ek olarak Horner ve diğerleri (2005), yaptığı bir araştırmada, tek denekli bir araştırmanın güvenilir sayılabilmesi için yöntemsel olarak 'kabul edilebilir' ölçütleri karşılayıp karşılamadığını belirlemeye yönelik- ele alınması gereken yedi kalite göstergesi belirlemiştir. Bu göstergeler; katılımcılar ve ortam, bağımlı değişken, bağımsız değişken, başlama düzeyi, iç geçerlik, diş geçerlik, sosyal geçerlik olmak üzere yedi maddede kategorize edilmiştir (Horner vd., 2005). Bir çalışmanın kalite göstergelerinin belirlenmesi, uygulanan müdahalenin bağımlı değişken üzerinde ne düzeyde anlamlı bir değişikliğe neden olduğunu anlamak için de önemlidir (Tankersley vd., 2008). Yüksek kaliteli bir araştırma, ilgili araştırmanın sonuçları hakkında farklı çıkarımlarda bulunmayı engellediği gibi bağımsız değişkenin etkisinin açık bir şekilde görülmesini sağlar. Bir çalışmanın kalite düzeyi ne kadar yüksek olursa, araştırmacı ve okuyucularda çalışmanın bulgularına olan güven o kadar yüksek olur (Odom vd., 2005). 
Yüksek kalite ölçütünü karşılayan çalışmalar arasında etkili bulunanlar, kanıt temelli uygulamaların ortaya çıkmasına zemin hazırlar (Odom vd., 2005). Kanıt temelli uygulama, 'çok sayıda, yüksek kaliteli, deneysel çalışmalarla desteklenen öğrenci kazanımları üzerinde olumlu etkileri olan öğretim uygulaması’ olarak tanımlanmaktadır. Kanıt temelli uygulama standartları, kanıt temelli uygulamaları sınıflandırırken çalışmaların belirli kalite göstergelerini karşılamasını gerektirir (Cook vd., 2019). Horner ve diğerleri (2005) tek denekli araştırmalarla bir uygulamanın kanıt temelli olduğuna karar verebilmek için en az beş araştırma yürütülmesi gerektiğini; bu çalışmalardan a) en az üç tanesinin kalite göstergelerini sağlaması ve hakemli bir dergide yayımlanmış olması, b) üç farklı coğrafi bölgede üç farklı araştırmacı ya da araştırma grubu ile yürütülmüş olması ve c) en az beş çalışmada toplam 20 katılımcı üzerinde uygulamanın olumlu etkisinin olması gerektiğini belirtmektedir. Yüksek kaliteli araştırmaların eğitimsel yansımaları da olumlu olmaktadır. Yüksek kaliteli araştırmalarda kullanılan müdahalenin eğitim ortamlarında uygulanma olasılığı artar. Ayrıca yüksek kaliteli araştırma bulguları ve eğitim ortamlarındaki uygulama sonuçlarının birbiriyle tutarlılı̆̆ı yüksek olmaktadır (Simmerman \& Swanson, 2001).

Alanyazında son çeyrek asır içerisinde, öğrenme güçlüğü olan ortaokul öğrencilerine yönelik uygulanan matematik müdahaleleri sistematik olarak gözden geçirildiğinde sınırlı sayıda araştırma olduğu görülmüştür (Maccini \& Hughes, 1997; Maccini vd., 2007; Marita \& Hord, 2017; Myers vd., 2015). Bu araştırmalardan üçü (Maccini \& Hughes, 1997; Maccini vd., 2007; Myers vd., 2015) kendi araştırmalarından daha önce yapılan araştırmaların genişletilmesi ve güncellenmesi amacını taşımaktadır. Bu doğrultuda, ilk olarak, Maccini ve Hughes (1997), 1988-2007 yılları arasında yapılan 43 araştırmayı; ikinci olarak, Maccini ve diğerleri (2007) 1995-2006 yılları arasında yapılmış 23 araştırmayı; üçüncü olarak, Myers ve diğerleri (2015), 2006-2014 yılları arasında yapılmış 15 araştırmay1; dördüncü ve son olarak, Marita ve Hord (2017) ise 2006-2014 yılları arasında yapılan 12 araştırmayı incelemiştir. Yapılan bu araştırmaların öğrenme güçlüğü olan öğrencilere yönelik uygulanan matematik müdahalelerinin araştırma temelli bir boyutunu oluşturmak için önemli olduğu vurgulanmaktadır (Lee vd., 2020). Belirtilen araştırmaların birincil amacının öğrenme güçlüğü olan ortaokul öğrencilerine yönelik uygulanan matematik problemi çözme müdahalelerinin incelenmesi olduğu belirtilmesine rağmen bu araştırmalarda öğrenme güçlüğü olan öğrencilerin katılımcı grupta az oranda yer almaları eleştirilmektedir (Lee vd., 2020). Bu bağlamda, Maccini ve diğerlerinin (2007) araştırmasında öğrencilerin \%34.1'inin; Myers ve diğerleri (2015) araştırmasında öğrencilerin \%25.2'sinin; Marita ve Hord (2017) araştırmasında ise öğrencilerin \%18.2'sinin öğrenme güçlüğü olan öğrencilerden oluştuğu bulunmuştur. Diğer katılımcıların yoğun olarak duygu davranış bozukluğu olan öğrenciler olduğu ve öğrencilerin öğrenim seviyelerinin de ortaokul dışında ilkokul ve lise düzeyini de içerdiği belirtilmiştir. Öğrenme güçlüğü olan öğrencilere yönelik araştırma bulgularının ayrı biçimde verilmemesi eleştirilen bir noktadır (Lee vd., 2020). Bu doğrultuda, bu araştırmada katılımcı makalelere ilişkin dahil edilme ölçütleri, daha önce yapılan araştırmalara yönelik gerçekleştirilen eleştiriler göz önüne alınarak oluşturulmuştur.

Türkiye'de özel eğitim alanında öğrencilerin problem çözme becerilerini destekleme amacıyla yapılan araştırmalarda, uygulanan müdahale programlarının etkilerinin incelendiği sınırlı sayıda araştırmaya rastlanmaktadır (Baki, 2014; Karabulut \& Özmen, 2018; Karabulut vd., 2015; Karakoç, 2002; Kot \& Y1kmış, 2018; Tufan \& Aykut, 2018; Tuncer, 2009). Bu araştırmalar da zihinsel yetersizlik, otizm spektrum bozukluğu ve görme yetersizliği olan öğrenciler ile yürütülmüştür. Öğrenme güçlüğü olan öğrenciler açısından alanyazın incelendiğinde, öğrencilerin matematik problemi çözme sırasında kullandığı bilişsel ve üstbilişsel stratejilerinin belirlendiği (Özkubat, 2019; Özkubat \& Özmen, 2018) araştırmalar bulunmasına karșın bu öğrencilerin problem çözme performanslarını arttırmaya yönelik herhangi bir müdahale programının etkilerinin incelendiği araştırmaya rastlanmamıştır. Özetle, öğrenme güçlüğünden farklı yetersizlik türlerine yönelik müdahale programlarının etkisi ve öğrenme güçlüğüne yönelik problem çözme sırasında kullanılan bilişsel ve üstbilişsel stratejiler incelenmiştir ancak öğrenme güçlüğüne yönelik müdahaleler incelenmemiştir. Bu gerekçeyle öğrenme güçlüğü olan öğrencilere yönelik olarak uygulanan matematik müdahalelerin incelenmesi önemli görülmektedir. Ayrıca Türkiye'de kalite göstergelerinin incelendiği matematik becerilerinin öğretimiyle ilgili iki (Aydın \& Tekin-İftar, 2019; Aydın vd., 2019) ve çoklu yetersizliğe sahip olan öğrencilerle yapılmış tek denekli araştırmaların incelendiği bir (EldenizÇetin vd., 2019) benzer çalışma bulunmaktadır. Bu araştırmalarda tek denekli araştırmalar için Horner ve diğerlerinin (2005) belirlediği kalite göstergeleri “evet/hayır” şeklinde değerlendirilmiştir. Yapılan bu araştırmada ise Jitendra ve diğerlerinin (2013) üçlü likert tipi puanlama sistemi kullanılarak daha detaylı bir değerlendirme yapılmıştır. Bu bağlamda, öğrenme güçlüğü olan öğrencilere yönelik olarak uygulanan matematik müdahalelerin betimsel olarak incelenmesi, böylece güncel uygulamaların ortaya konularak, belirlenen uygulamaların öğrenme güçlüğü olan öğrencilerin eğitiminde kullanılabilmesi için yol gösterici olacağ1 düşünülmektedir. Ek olarak, bu araştırmada incelenen müdahalelerin kalite göstergeleri açısından değerlendirilmesi ileride yapılacak olan 

MÜDAHALELERİ: KAPSAMLI ALANYAZIN İNCELENMESI

araştırmalara yöntemsel olarak fikir vermesi açısından da önemli görülmektedir. Böylece Türkiye'de öğrenme güçlüğü olan öğrencilere yönelik araştırmaların planlanması, uygun müdahale programlarının geliştirilmesi ve kanıt temelli uygulamaların kullanılması mümkün olacaktır. Bu kapsamda, yapılan bu araştırmada ortaokul düzeyinde bulunan öğrenme güçlügü olan öğrencilere yönelik; a) son 20 yılda geliştirilen matematik problem çözme müdahalelerinin derlenmesi, b) betimsel olarak bu araştırmaların özelliklerinin listelenmesi ve c) araştırmaların kalite göstergeleri açısından incelenmesi amaçlanmaktadır.

\section{Yöntem}

Bu araştırma, 2000-2020 yılları arasında, ortaokul düzeyinde öğrenme güçlüğü olan öğrenciler ile yürütülen matematik problem çözme müdahalelerini içeren, hakemli dergilerde yayınlanmış araştırmaları kapsamaktadır. Bu bölümde sırasıyla, katılımcı makalelerin araştırmaya dahil edilme ölçütleri, alanyazın taraması, katılımcı makalelerin kodlanması, makalelerin betimsel analiz süreci, kalite göstergeleri analiz süreci ve kodlayıcılar arası güvenirlik başlıklarına yer verilmiştir.

\section{Katılımcı Makalelerin Araştırmaya Dahil Edilme ve Dışlanma Ölçütleri}

Araştırmada, katılımcı makalelerin bu araştırmaya dahil edilmesine ve edilmemesine ilişkin bazı temel seçim ölçütleri belirlenmiştir. Bu ölçütler; a) araştırmaların 2000-2020 yılları arasında yayınlanmış olması, b) araştırmaların katılımcı grubunun öğrenme güçlüğü olan ortaokul düzeyinde öğrencileri içermesi, c) araştırmanın bağımsız değişkeni olarak matematik problem çözme müdahalesini içermesi, d) araştırma desenlerinin tek denekli deneysel desenlerden olması ve e) hakemli bir dergide yayınlanmış olması olarak belirlenmiştir. Araştırmaya katılımcı makalelerin dahil edilmemesine neden olan temel seçim ölçütleri ise; a) araştırmada öğrenme güçlüğü olan öğrencilerin açıklıkla tanımlanmaması ve aynı öğrencinin ek olarak diğer yetersizliklerden (örn., duygu davranış bozukluğu, dikkat eksikliği ve hiperaktivite vb.) etkilenmiş olması, b) öğrencilerin çoğunluğunun ortaokul düzeyinde bulunmaması ve c) uygulanan müdahale stratejileri sonrasında öğrenme güçlüğü olan öğrencilere ilişkin bulguların ayrı biçimde verilmemesi olarak belirlenmiştir.

\section{Alanyazın Taraması}

$\mathrm{Bu}$ araştırmanın katılımcı makalelerin belirlenmesi tespit etme, tarama, uygunluk ve dahil etme aşamaları olmak üzere dört adımda gerçekleştirlmiştir. İlk adımda, ULAKBİM ulusal veritabanları (UVT), EBSCOhost, Education Research Complete, Education Resources Information Center (ERIC), Web of Science, Psychological Abstracts Index (PsycINFO), Google ve Google Akademik arama motorları kullanılmıştır. Belirtilen arama motorlarına anahtar kelimeler girilerek tarama gerçekleştirilmiştir. Taramalarda kullanılan anahtar kelimeler Türkçe ve İngilizce olarak aranmıştır. Kullanılan anahtar kelimeler, öğrenme güçlüğü (learning disability), problem çözme (problem solving), matematik müdahalesi (math intervention), matematik programı (math program), matematik öğretimi (math instruction), matematik performansı (math performance), matematik akademik başarısı (math academic achievement), orta okul (middle school), 6. sinıf (grade 6), 7. sinıf (grade 7), 8. sinıf (grade 8), kesirler (fractions), hesaplama (computation), cebir (algebra), geometri (geometry), aritmetik (arithmetic)'tir. Belirtilen anahtar kelimeler ile yapılan tarama sonucunda 142 araştırmaya ulaşılmıştır. Íkinci adımda, ulaşılan araştırmaların başlıkları, özetleri ve anahtar kelimeleri incelenmiş, kitap bölümü, rapor, betimsel ve meta analiz vb. olanlar elenerek 100 araştırma elde edilmiştir. Ayrıca ilgili alanyazının anahtar dergileri olarak nitelendirilen, özel gereksinimli öğrencilere uygulanan problem çözme müdahalelerinin sıklıkla yer aldığı, Exceptional Children, Journal of Learning Disabilities, Learning Disabilities Quarterly, Learning Disabilities Research \& Practice, Remedial \& Special Education ve Journal of Special Education dergilerinde çıkan makaleler incelenmiştir. Yapılan inceleme sonucu iki araştırma daha elde edilmiştir. Üçüncü adımda, öğrenme güçlüğü olan öğrenciler ile yürütülen matematik problem çözme müdahalelerine ilişkin 40 makale incelenmiştir. Bu makalelerden 31'i araştırmanın katılımcı grubunun sınıf düzeyi değişkenini karşılamadığından ve araştırma desenleri açısından uygunluk göstermediğinden, diğer bir ifade ile tek denekli desenleri içermediğinden elenmiştir. Dördüncü adımda ise, bu araştırmanın araştırmaya dahil edilme ölçütlerini karşılayan dokuz araştırma elde edilmiştir. Alanyazın taramasında gerçekleştirilen süreç Şekil 1'de yer almaktadır. 


\section{Sekil 1}

\section{Alanyazın Tarama süreci}

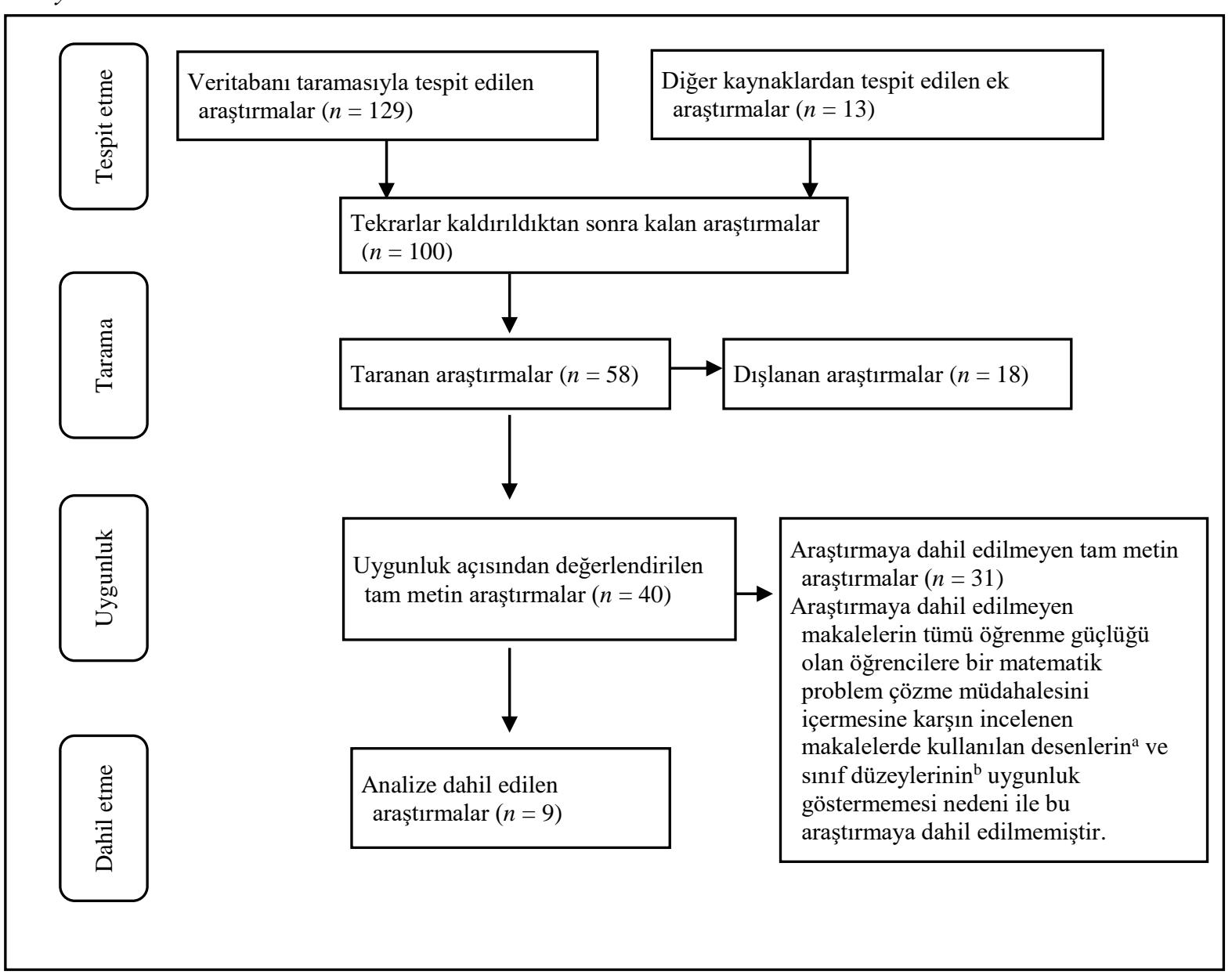

Not: "Moher, D., Liberati, A., Tetzlaff, J., \& Altman, D. G. (2009). Preferred reporting items for systematic reviews and meta-analyses: The PRISMA statement. Annals of Internal Medicine, 151(4), 264-269." kaynağından uyarlanmıștır.

aBottge \& Cho, 2013; Bottge vd., 2001; Bottge vd., 2002; Bottge vd., 2003; Bottge vd., 2014; Bottge, Rueda vd., 2010; Bottge, Grant vd., 2010; Bottge, Rueda, LaRoque vd, 2007; Bottge, Rueda, Serlin vd., 2007; Butler vd., 2003; Calhoon \& Fuchs, 2003; Iseman \& Naglieri, 2011; Krawec vd., 2013; Manalo vd., 2000; Montague vd., 2014; Montague vd., 2011; Naglieri \& Johnson, 2000; Scarlato \& Burr, 2002; Wildmon vd., 2004; Witzel vd., 2003; Witzel, 2005; Xin vd., 2005.

bJitendra vd., 2007; Maccini \& Hughes, 2000; Morin vd., 2017; Satsangi \& Bouck, 2015; Satsangi vd., 2018; Satsangi vd., 2016; Sharp \& Dennis, 2017; Strickland \& Maccini, 2013; Xin, 2008.

Tüm tarama süreci yazarlar tarafindan yürütülmüştür. Tarama sonucunda altı farklı dergide, katılımcı makalelerin dahil edilme ve dişlanma ölçütleri göz önüne alınarak toplam dokuz araştırmaya ulaşılmıştır. Araştırma kapsamına incelenen makaleler kaynaklar kısmında (*) imi ile belirtilmiştir.

\section{Katılımcı Makalelerin Kodlanması}

Katılımcı makalelerin dahil edilmesine ilişkin temel seçim ölçütleri göz önüne alınarak makalelerin seçimi gerçekleştirilmiştir. Öncelikle, belirtilen temel seçim ölçütleri dikkate alınarak bir form hazırlanmıştır. Makalelerin tümü yazarlar tarafından ayrıntılı olarak incelenerek hazırlanan forma kaydedilmiştir.

\section{Betimsel Analiz Süreci}

Araştırmaya dahil edilen makaleler, araştırma inceleme formunda yer alan değişkenler doğrultusunda incelenerek; a) katılımcı sayısı, b) sınıf ve yaş düzeyi, c) cinsiyet, d) hedef beceri, e) problem türü, f) araştırma deseni, g) uygulama ortamı, h) genelleme ve izleme, i) güvenirlik, j) sosyal geçerlik ve k) bulgular başlıkları altında değerlendirilmiştir. İncelenen araştırmalara ilişsin bilgiler Tablo 1, 2 ve 3 'te yer almaktadır. 


\section{Kalite Göstergeleri Analiz Süreci}

Kalite Göstergeleri Analiz Formu, Jitendra ve diğerleri (2013) tarafindan geliștirilen, tek denekli araştırmaların kalitelerini belirlemek için kullanılan informal bir araçtır. Form yedi bölümden oluşmaktadır. Katılımcılar ve ortam bölümünde üç madde; bağımlı değişken bölümünde beş madde; bağımsız değişken bölümünde üç madde; başlama düzeyi bölümünde iki madde; iç geçerlik bölümünde üç madde; dış geçerlik bölümünde bir madde ve sosyal geçerlik bölümünde dört madde olmak üzere toplam 21 maddeden oluşmaktadır. Jitendra ve diğerleri (2013) tek denekli araştırmalar için kalite göstergeleri formunu geliştirirken Horner ve diğerlerinin (2005) tek denekli desenler için kalite göstergelerini temel almışlardır. Horner ve diğerlerinin (2005) araştırmasında yer alan kalite göstergelerini kullanarak, Jitendra ve diğerlerinin (2001) araştırmasındaki matematik müdahaleleri ile ilgili ifadelerini de içerecek şekilde gerekli uyarlamalar yapılmıştır. Horner ve diğerlerinin (2005) belirlediği kalite göstergeleri için "Evet/Hayır" şeklindeki değerlendirme sistemi, 1, 2 ve 3 şeklinde puanlama sistemine dönüştürülmüştür. Bu doğrultuda oluşturulan form, her bir madde için 3'lü Likert tipte, göstergeyi karşıllyor (3), göstergeyi kısmen karşılıyor (2) ve göstergeyi karşlamıyor (1) şeklinde puanlama sistemine sahiptir. Formdan elde edilen toplam puan, 21 ile 63 puan arasında değişmektedir. Bir araştırmanın, kalite göstergelerini karşılaması bakımından yüksek kaliteli olarak değerlendirilebilmesi için; a) formu oluşturan yedi temel kalite göstergenin her birinin iki ve üzeri puan alması, b) yedi temel kalite göstergesini oluşturan 21 bileșenin her birinin en az bir puan alması gerekmektedir (Jitendra vd., 2013).

Kalite Göstergeleri Analiz Formu bu araştırmada kullanılmadan önce form Türkçe’ye çevrilmiştir. Çeviri açısından İngilizce'yi iyi derecede bilen bir dil uzmanının görüşleri alınmıştır. Dil uzmanı dönütleri doğrultusunda gerekli düzeltmeler yapıldıktan sonra Türkçe form özel eğitim alanında uzman iki akademisyene verilerek uzman görüşü alınmıştır. Uzman görüşü formu 5'li Likert tipte hazırlanmıştır. Bu form, (5) kesinlikle uygun, (4) uygun, (3) kararsızım, (2) uygun değil ve (1) kesinlikle uygun değil şeklinde hazırlanmıştır. Uzman görüşü formu kalite göstergelerinin; açıklık, anlaşılırlık ve incelenecek konuyu kapsama bakımından değerlendirilmesini içermektedir. Form içerisinde yer alan maddeler iki uzmandan da en az 4 ve üzeri puan almış ve uzmanların belirttiği düzeltmeler yapılmıştır.

\section{Kodlayıcılar Arası Güvenirlik}

Araştırmada kodlayıcılar arası güvenirlik, elde edilen araştırmaların tümünde, "Görüş birliği / (Görüş birliği + Görüş ayrılığı) X 100” formülü kullanılarak hesaplanmıştır (House vd., 1981).

\section{Bulgular}

$\mathrm{Bu}$ araştırmalara ilişkin bulgular; betimsel analiz, kalite göstergeleri ve kodlayıcılar arası güvenirlik bulguları olarak üç başlık altında incelenmiştir.

\section{Betimsel Analiz Bulguları}

\section{Katilimcilar}

Araştırmalarda yer alan öğrenme güçlüğü tanılı katılımcılar, a) katılımcı sayısı, b) sınıf ve yaş düzeyi ve c) cinsiyet değişkenleri bakımından incelenmiştir. Araştırmalarda yer alan katılımcılara ilişkin bilgileri Tablo 1'de yer almaktadır.

\section{Tablo 1}

Katılımcılara İlişkin Bilgileri

\begin{tabular}{|c|c|c|c|}
\hline Araştırmalar & Kat1lımc1 say1s1 & Sınıf/Yaş düzeyi & Cinsiyet \\
\hline Cass vd. (2003) & 3 & 7-10. sınıf/13-16 yaş & $2 \mathrm{E}, 1 \mathrm{~K}$ \\
\hline Freeman-Green vd. (2015) & 6 & 8. sinıf/12-16 yaş & $6 \mathrm{E}$ \\
\hline Hunt \& Vasquez (2014) & 3 & 6-7. sınıf/11-14 yaş & $1 \mathrm{E}, 2 \mathrm{~K}$ \\
\hline Jitendra vd. (2002) & 4 & 8. sınıf/13 yaş & $2 \mathrm{E}, 2 \mathrm{~K}$ \\
\hline Joseph \& Hunter (2001) & 3 & $13-14$ yaş & $3 \mathrm{E}$ \\
\hline Maccini \& Ruhl (2000) & 3 & 8. $\sin 1 f$ & $3 \mathrm{E}$ \\
\hline Scheuermann vd. (2009) & 14 & $12-14$ yaş & $10 \mathrm{E}, 4 \mathrm{~K}$ \\
\hline Test \& Ellis (2005) & 6 & 6. sinif & $5 \mathrm{E}, 1 \mathrm{~K}$ \\
\hline Van Garderen (2007) & 3 & 8. sinıf/13-14 yaş & $2 \mathrm{E}, 1 \mathrm{~K}$ \\
\hline
\end{tabular}

Not: E = erkek; K = kız. 
Tablo 1 incelendiğinde, araştırmalarda toplam 45 öğrenme güçlüğü olan katılımcı bulunmaktadır. Katılımcıların 34'ü (\%76) erkek ve 11'i (\%24) kızdır. Katılımcıların \%54'ünün $(n=24)$ 11-13 yaş aralığında, \%33'ünün $(n=15)$ 14-16 yaş aralığında yer aldığı bulunmuştur. Araştırmalarda yer alan katılımcılar sınıf düzeyi değişkeni incelendiğinde, katılımcıların \%27'sinin $(n=12) 6$.sınıf düzeyinde oldukları, \%13'ünün $(n=7) 7$.sınıf düzeyinde oldukları ve yaklaşık yarısının da 8.sınıf düzeyinde oldukları belirlenmiştir. Katılımcıların \%13'ünün $(n=6)$ yaş düzeyi, \%6'sının ise $(n=3)$ sınıf düzeyi belirtilmemiştir.

\section{Araştırmaların Betimleyici Bilgileri}

Araştırmalar; a) hedef beceri, b) problem türü, c) araştırma deseni ve d) uygulama ortamı bakımından incelenmiştir. Araştırmaların betimleyici bilgileri Tablo 2'de görülmektedir.

\section{Tablo 2}

Araştırmaların Betimleyici Bilgileri

\begin{tabular}{|c|c|c|c|c|}
\hline Araştırmalar & Hedef beceri & Problem türü & Araştırma deseni & Uygulama ortamı \\
\hline Cass vd. (2003) & $\begin{array}{l}\text { Doğrudan öğretim ve somut- } \\
\text { yarı somut-soyut stratejisi ile } \\
\text { problem çözme }\end{array}$ & $\begin{array}{l}\text { Çevre ve alan } \\
\text { problemleri }\end{array}$ & $\begin{array}{l}\text { Denekler arası çoklu } \\
\text { başlama modeli }\end{array}$ & $\begin{array}{l}\text { Destek eğitim } \\
\text { sınıfı }\end{array}$ \\
\hline $\begin{array}{l}\text { Freeman-Green vd. } \\
\text { (2015) }\end{array}$ & $\begin{array}{l}\text { SOLVE stratejisi ile problemi } \\
\text { çözme }\end{array}$ & $\begin{array}{l}\text { Dört işlem } \\
\text { problemleri }\end{array}$ & $\begin{array}{l}\text { Denekler arası çoklu } \\
\text { yoklama modeli }\end{array}$ & Özel eğitim sınıfı \\
\hline $\begin{array}{l}\text { Hunt \& Vasquez } \\
(2014)\end{array}$ & $\begin{array}{l}\text { Somut-yarı somut-soyut } \\
\text { stratejisi ile problem çözme }\end{array}$ & $\begin{array}{l}\text { Yüzde ve oran } \\
\text { problemleri }\end{array}$ & $\begin{array}{l}\text { Denekler arası çoklu } \\
\text { başlama modeli }\end{array}$ & $\begin{array}{l}\text { Destek eğitim } \\
\text { sinıfı }\end{array}$ \\
\hline Jitendra vd. (2002) & Şema temelli problem çözme & $\begin{array}{l}\text { Değişim } \\
\text { problemleri }\end{array}$ & $\begin{array}{l}\text { Denekler arası çoklu } \\
\text { yoklama modeli }\end{array}$ & $\begin{array}{l}\text { Genel eğitim } \\
\text { sinıfı }\end{array}$ \\
\hline $\begin{array}{l}\text { Joseph \& Hunter } \\
\text { (2001) }\end{array}$ & $\begin{array}{l}\text { Öz düzenleme stratejisi ve } \\
\text { ipucu kartları ile problem } \\
\text { çözme }\end{array}$ & Kesir problemleri & $\begin{array}{l}\text { Denekler arası çoklu } \\
\text { başlama modeli }\end{array}$ & Belirtilmemiştir \\
\hline $\begin{array}{l}\text { Maccini \& Ruhl } \\
\text { (2000) }\end{array}$ & $\begin{array}{l}\text { STAR stratejisi ile problem } \\
\text { çözme }\end{array}$ & $\begin{array}{l}\text { Dört işlem } \\
\text { problemleri }\end{array}$ & $\begin{array}{l}\text { Denekler arası çoklu } \\
\text { yoklama modeli }\end{array}$ & $\begin{array}{l}\text { Okuldaki boş bir } \\
\text { sinıf }\end{array}$ \\
\hline $\begin{array}{l}\text { Scheuermann vd. } \\
\text { (2009) }\end{array}$ & $\begin{array}{l}\text { Açık anlatım ile problem } \\
\text { çözme }\end{array}$ & $\begin{array}{l}\text { Tek bilinmeyenli } \\
\text { denklemler }\end{array}$ & $\begin{array}{l}\text { Denekler arası çoklu } \\
\text { başlama modeli }\end{array}$ & $\begin{array}{l}\text { Okuldaki boş bir } \\
\text { sinıf }\end{array}$ \\
\hline Test \& Ellis (2005) & $\begin{array}{l}\text { LAP stratejisi ile problem } \\
\text { çözme }\end{array}$ & Kesir problemleri & $\begin{array}{l}\text { Denekler arası çoklu } \\
\text { yoklama modeli }\end{array}$ & Özel eğitim sınıfı \\
\hline $\begin{array}{l}\text { Van Garderen } \\
(2007)\end{array}$ & Görsel stratejiler ile Solve It! & $\begin{array}{l}\text { Dört işlem } \\
\text { problemleri }\end{array}$ & $\begin{array}{l}\text { Denekler arası çoklu } \\
\text { yoklama modeli }\end{array}$ & $\begin{array}{l}\text { Okuldaki boş bir } \\
\text { sinıf }\end{array}$ \\
\hline
\end{tabular}

Araştırmaların desenleri incelendiğinde, desenlerin yaklaşık olarak eşit dağılım gösterdikleri, denekler arası çoklu başlama deseninin dört araştırmada (\%44), denekler arası çoklu yoklama deseninin ise beş araştırmada (\%56) kullanıldığı belirlenmiştir. Araştırmaların uygulama ortamları incelendiğinde ise araştırmaların \%44'ünün $(n=4)$ özel eğitim ve destek eğitim sınıfında, \%33'ünün $(n=3)$ okuldaki boş bir sınıf içinde uygulandıkları görülmektedir. Bir araştırmada ise (\%11) uygulamanın genel eğitim sınıfında yapıldığı belirtilmiştir. Hedef beceri olarak problem çözme becerisi öğretilirken doğrudan öğretim, somut-yarı somut-soyut stratejisi, şema temelli yaklaşım, öz düzenleme stratejisi ve ipucu kartları, STAR stratejisi, açık anlatım, LAP stratejisi, görsel stratejiler, Solve It! ve SOLVE stratejisi kullanılmıştır. Ayrıca araştırmalarda çevre ve alan, yüzde ve oran, değişim, kesir, dört işlem ve tek bilinmeyenli denklem gibi problem türleri üzerinde çalışılmıştır.

\section{Araştırma Sonuçları}

Araştırmaların sonuçları, a) genelleme ve izleme, b) gözlemciler arası ve uygulama güvenirliği ve c) sosyal geçerlik değişkenleri bakımından incelenmiştir. Araştırmaların uygulamaya ilişkin bilgileri Tablo 3'te görülmektedir. 
Tablo 3

\begin{tabular}{|c|c|c|c|c|}
\hline Araştırmalar & $\begin{array}{l}\text { Genelleme/ } \\
\text { izleme }\end{array}$ & $\begin{array}{l}\text { Güvenirlik } \\
\text { GAG/UG }\end{array}$ & $\begin{array}{c}\text { Sosyal } \\
\text { geçerlik }\end{array}$ & Sonuçlar \\
\hline Cass vd. (2003) & $-/+$ & $+/+$ & + & $\begin{array}{l}\text { Öğrenciler problem çözme becerisini kazanmıştır. Bu } \\
\text { beceri iki ay sonra alınan izleme verilerinde de kalıcılığını } \\
\text { sürdürmüştür. Ayrıca kazanılan beceri, kâğıt kalem } \\
\text { kullanarak problem çözme becerisine genellenmiştir. }\end{array}$ \\
\hline $\begin{array}{l}\text { Freeman-Green } \\
\text { vd. }(2015)\end{array}$ & $+/+$ & $+/+$ & + & $\begin{array}{l}\text { Uygulanan SOLVE stratejisi ile öğrencilerin matematik } \\
\text { problemi çözme doğruluğu artmıştır ve öğrenilen } \\
\text { becerilerde genelleme sağlanmıştır. Müdahaleden iki ve } \\
\text { altı hafta sonra yapılan ölçümlerde öğrenilen becerilerin } \\
\text { kalıcılığını sürdürdüğü görülmüştür. }\end{array}$ \\
\hline $\begin{array}{l}\text { Hunt \& Vasquez } \\
\text { (2014) }\end{array}$ & $-/-$ & $+/+$ & - & $\begin{array}{l}\text { Yapılan müdahale ile üç öğrencinin de problem çözme } \\
\text { performansları artırmıştır. Müdahale süreci sonucunda } \\
\text { öğrencilerin strateji kullanım düzeyleri de artmıştır. }\end{array}$ \\
\hline $\begin{array}{l}\text { Jitendra vd. } \\
(2002)\end{array}$ & $+/+$ & $+/+$ & - & $\begin{array}{l}\text { Şema temelli problem çözme stratejisi, araştırmada yer alan } \\
\text { dört öğrencinin de problem çözme doğruluğunu arttırmada } \\
\text { etkili bulunmuştur. }\end{array}$ \\
\hline $\begin{array}{l}\text { Joseph \& Hunter } \\
(2001)\end{array}$ & $-/+$ & $+/-$ & - & $\begin{array}{l}\text { Kesir problemleri çözmede ipucu kartlarının kullanımı ile } \\
\text { müdahale uygulaması üç ögrencinin de problem çözme } \\
\text { becerilerini geliştirmiştir. Müdahalenin ardından birer } \\
\text { hafta arayla alınan üç yoklama verisinde kalıcılığın } \\
\text { sağlandığı görülmüştür. }\end{array}$ \\
\hline $\begin{array}{l}\text { Maccini \& Ruhl } \\
(2000)\end{array}$ & $+/+$ & $+/+$ & + & $\begin{array}{l}\text { STAR stratejisinin öğrencilerin problem çözme } \\
\text { becerilerinin geliştiği belirlenmiştir. Problem çözme farklı } \\
\text { problem türlerine genellenmiş ve iki ve üç hafta sonra } \\
\text { yapılan ölçümlerde kalıcılığını sürdürmüştür. }\end{array}$ \\
\hline $\begin{array}{l}\text { Scheuermann vd. } \\
\text { (2009) }\end{array}$ & $+/+$ & $+/-$ & - & $\begin{array}{l}\text { Tek bilinmeyenli matematik problemi çözmede açık } \\
\text { anlatım yöntemi kullanılmasının etkili olduğu } \\
\text { belirlenmiştir. Ayrıca öğrencilerin bu beceriyi daha } \\
\text { karmaşık problemlere de genelledikleri belirlenmiştir. } \\
\text { Öğretimi yapılan becerilerin } 11 \text { hafta sonra yapılan } \\
\text { ölçümlerde kalıcılığını sürdürdüğü görülmüştür. }\end{array}$ \\
\hline $\begin{array}{l}\text { Test \& Ellis } \\
(2005)\end{array}$ & $-/+$ & $+/-$ & + & $\begin{array}{l}\text { LAP stratejisi kesir problemi çözme üzerinde altı öğrenci } \\
\text { için de etkili bulunmuştur. }\end{array}$ \\
\hline $\begin{array}{l}\text { Van Garderen } \\
\text { (2007) }\end{array}$ & $+/+$ & $+/-$ & - & $\begin{array}{l}\text { Matematik problemi çözmede görselleştirme stratejisi } \\
\text { öğrencilerin matematik problemi çözme performansı } \\
\text { artırmıştır. }\end{array}$ \\
\hline
\end{tabular}

Not: GAG = gözlemciler arası güvenirlik; $\mathrm{UG}=$ uygulama güvenirliği

$\mathrm{Bu}$ araştırmada incelenen dokuz çalışmanın görsel grafiklerinin ve yazılı bulgularının incelenmesi sonucunda, çeşitli problem çözme öğretim müdahalelerinin hedef becerilerin kazanımında etkili olduğu belirlenmiş̧tir. Problem çözme müdahalelerinin ele alındığı tek denekli deneysel desenlerin grafikleri incelendiğinde, başlama düzeyindeki eğrilerin uygulama evrelerinde artış eğimine sahip olduğu belirlenmiştir.

\section{Kalite Göstergeleri Bulguları}

Araştırmaların kalite göstergelerine yönelik a) katılımcılar ve ortam, b) bağımlı değişken, c) bağımsız değişken, başlama düzeyi, d) deneysel kontrol/iç geçerlik, e) dış geçerlik ve f) sosyal geçerliğine ilişkin bilgiler Tablo 4'te yer almaktadır. Her araştırma, yöntemsel olarak kabul edilebilir standartları karşılama durumuna göre değerlendirilmiştir. 
Tablo 4

Kalite Göstergeleri Tablosu

\begin{tabular}{|c|c|c|c|c|c|c|c|c|c|}
\hline & 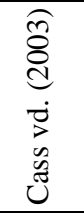 & 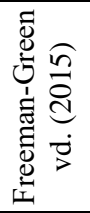 & 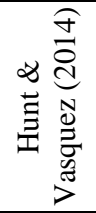 & 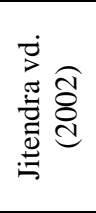 & 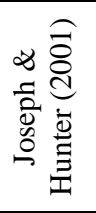 & 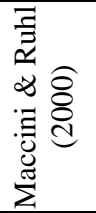 & 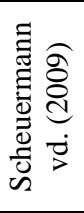 & 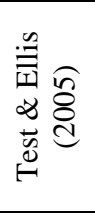 & 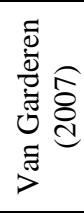 \\
\hline \multicolumn{10}{|l|}{ Katılimcilar ve ortam } \\
\hline Katılımciların tanımlanması & 3 & 3 & 3 & 3 & 3 & 3 & 3 & 3 & 3 \\
\hline Katılımcıların seçimi & 3 & 3 & 3 & 3 & 3 & 3 & 3 & 2 & 3 \\
\hline Ortamların tanımlanması & 2 & 1 & 3 & 3 & 1 & 2 & 2 & 2 & 2 \\
\hline Ortalama & 2.66 & 2.33 & 3 & 3 & 2.33 & 2.66 & 2.66 & 2.33 & 2.66 \\
\hline \multicolumn{10}{|l|}{ Bağımlı değişken } \\
\hline $\begin{array}{l}\text { Bağımlı değişkenin } \\
\text { tanımlanması }\end{array}$ & 1 & 3 & 2 & 3 & 2 & 3 & 3 & 3 & 3 \\
\hline Ölçme işlemleri & 2 & 3 & 3 & 3 & 3 & 3 & 3 & 3 & 3 \\
\hline $\begin{array}{l}\text { Ölçme geçerliği ve } \\
\text { tanımlanması }\end{array}$ & 2 & 3 & 3 & 3 & 2 & 3 & 3 & 2 & 2 \\
\hline Ölçme sıklığ1 & 3 & 2 & 3 & 3 & 3 & 1 & 2 & 3 & 2 \\
\hline Ölçme güvenirliği & 2 & 3 & 3 & 3 & 2 & 3 & 3 & 1 & 3 \\
\hline Ortalama & 2 & 2.8 & 2.8 & 3 & 2.4 & 2.6 & 2.8 & 2.4 & 2.6 \\
\hline \multicolumn{10}{|l|}{ Bağımsız değişken } \\
\hline $\begin{array}{l}\text { Bağımsız değişkenin } \\
\text { tanımlanması }\end{array}$ & 3 & 3 & 2 & 3 & 2 & 3 & 3 & 3 & 3 \\
\hline $\begin{array}{l}\text { Bağımsız değişkenin } \\
\text { manipülasyonu }\end{array}$ & 3 & 3 & 3 & 3 & 3 & 3 & 3 & 3 & 3 \\
\hline Uygulama güvenirliği & 3 & 3 & 3 & 3 & 1 & 3 & 1 & 1 & 1 \\
\hline Ortalama & 3 & 3 & 2.66 & 3 & 2 & 3 & 2.33 & 2.33 & 2.33 \\
\hline \multicolumn{10}{|l|}{ Başlama düzeyi } \\
\hline $\begin{array}{l}\text { Bağımlı değişkenin } \\
\text { ölçümlenmesi }\end{array}$ & 3 & 3 & 2 & 3 & 2 & 2 & 3 & 2 & 2 \\
\hline $\begin{array}{l}\text { Başlama düzeyi koşullarının } \\
\text { tanımlanması }\end{array}$ & 2 & 3 & 2 & 3 & 2 & 2 & 3 & 3 & 2 \\
\hline Ortalama & 2.5 & 3 & 2 & 3 & 2 & 2 & 3 & 2.5 & 2 \\
\hline \multicolumn{10}{|l|}{ Deneysel kontrol/iç geçerlik } \\
\hline Deneysel etki & 3 & 3 & 3 & 3 & 3 & 2 & 2 & 3 & 3 \\
\hline İç geçerlik & 3 & 3 & 3 & 3 & 3 & 2 & 2 & 3 & 3 \\
\hline İç geçerlik sonuçları & 2 & 3 & 3 & 3 & 3 & 2 & 2 & 3 & 3 \\
\hline Ortalama & 2.33 & 3 & 3 & 3 & 3 & 2 & 2 & 3 & 3 \\
\hline \multicolumn{10}{|l|}{ Dış geçerlik } \\
\hline Tekrar edilebilir etkiler & 2 & 3 & 2 & 3 & 2 & 3 & 3 & 2 & 3 \\
\hline Ortalama & 2 & 3 & 2 & 3 & 2 & 3 & 3 & 2 & 3 \\
\hline
\end{tabular}

Özkubat vd. 
Tablo 4 (devami)

\begin{tabular}{|c|c|c|c|c|c|c|c|c|c|}
\hline & $\begin{array}{l}\text { శิ } \\
\text { d } \\
\dot{0} \\
\dot{0} \\
\tilde{z} \\
\tilde{z}\end{array}$ & 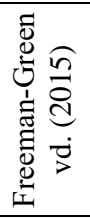 & 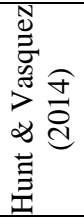 & 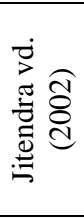 & 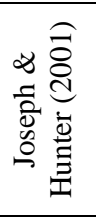 & 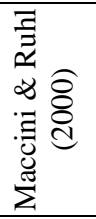 & 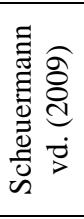 & 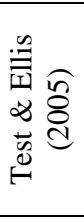 & 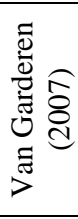 \\
\hline \multicolumn{10}{|l|}{ Sosyal geçerlik } \\
\hline $\begin{array}{l}\text { Bağımlı değişkenin sosyal } \\
\text { önemi }\end{array}$ & 1 & 3 & 1 & 3 & 1 & 3 & 1 & 2 & 1 \\
\hline $\begin{array}{l}\text { Bağımlı değişkende } \\
\text { meydana gelen değiş̧imin } \\
\text { önem büyüklüğ̈ü }\end{array}$ & 3 & 3 & 3 & 3 & 3 & 3 & 3 & 3 & 2 \\
\hline $\begin{array}{l}\text { Bağımsız değişken } \\
\text { uygulamasının uygulama } \\
\text { kolaylığı ve maliyet } \\
\text { verimliliği }\end{array}$ & 2 & 3 & 1 & 3 & 1 & 3 & 1 & 2 & 1 \\
\hline $\begin{array}{l}\text { Bağımsız değişkenin } \\
\text { uygulama durumu }\end{array}$ & 2 & 2 & 2 & 3 & 2 & 2 & 2 & 2 & 2 \\
\hline Ortalama & 2 & 2.75 & 1.75 & 3 & 1.75 & 2.75 & 1.75 & 2.25 & 1.5 \\
\hline
\end{tabular}

\section{Katılımcilar ve Ortam}

İncelenen araştırmaların \%78'i $(n=7)$ katılımcı ve ortam bakımından yükssek kalite standartlarını karşılamaktadır (Cass vd., 2003; Hunt \& Vasquez, 2014; Jitendra vd., 2002; Maccini \& Ruhl, 2000; Scheuermann vd., 2009; Test \& Ellis, 2005; Van Garderen, 2007). Araştırmaların \%22'si $(n=2)$ ortamların tanımlanması maddesinden 1 puan alarak kalite göstergelerini karşılamadığ görülmüştür (Freeman-Green vd., 2015; Joseph \& Hunter, 2001). Ayrıca araştırmaların \%22'si $(n=2)$ değerlendirmeden tam puan almıştır (Hunt \& Vasquez, 2014; Jitendra vd., 2002).

\section{Bağımlı Değișken}

İncelenen araştırmaların \%67'si $(n=6)$ bağımlı değişken bakımından yüksek kalite standartlarını karşılamaktadır (Freeman-Green vd., 2015; Hunt \& Vasquez, 2014; Jitendra vd., 2002; Joseph \& Hunter, 2001; Scheuermann vd., 2009; Van Garderen, 2007). Araştırmaların \%33'ünün $(n=3)$ bağımlı değişkenin tanımlanması, ölçme sıklığı ve ölçme güvenirliği maddelerinden 1 puan alarak kalite göstergelerini karşılamadığı görülmüştür (Cass vd., 2003; Maccini \& Ruhl, 2000; Test \& Ellis, 2005). Ayrıca araştırmaların \%11'i $(n=1)$ değerlendirmeden tam puan almıştır (Jitendra vd., 2002).

\section{Bă̆ımsız, Değgişken}

İncelenen araştırmaların \%56'sı $(n=5)$ bağımsız değişken bakımından yüksek kalite standartlarını karşılamaktadır (Cass vd., 2003; Freeman-Green vd., 2015; Hunt \& Vasquez, 2014; Jitendra vd., 2002; Maccini \& Ruhl, 2000). Araştırmaların \%44'ünün $(n=4)$ uygulama güvenirliği maddesinden 1 puan alarak kalite göstergelerini karşılamadığı görülmüştür (Joseph \& Hunter, 2001; Scheuermann vd., 2009; Test \& Ellis, 2005; Van Garderen, 2007). Ayrıca araştırmaların \%44'ü $(n=4)$ değerlendirmeden tam puan almıştır (Cass vd., 2003; Freeman-Green vd., 2015; Jitendra vd., 2002; Maccini \& Ruhl, 2000).

\section{Başlama Düzeyi}

İncelenen araştırmaların \%100'ü $(n=9)$ başlama düzeyi bakımından yüksek kalite standartlarını karş1lamaktadır (Cass vd., 2003; Freeman-Green vd., 2015; Hunt \& Vasquez, 2014; Jitendra vd., 2002; Joseph \& Hunter, 2001; Maccini \& Ruhl, 2000; Scheuermann vd., 2009; Test \& Ellis, 2005; Van Garderen, 2007). Ayrica araştırmaların \%33'ü $(n=3)$ değerlendirmeden tam puan almıştır (Freeman-Green vd., 2015; Jitendra vd., 2002; Scheuermann vd., 2009).

\section{Deneysel Kontrol/Iç Geçerlik}

İncelenen araştırmaların \%100’ü $(n=9)$ deneysel kontrol/iç geçerlik bakımından yüksek kalite standartlarını karşılamaktadır (Cass vd., 2003; Freeman-Green vd., 2015; Hunt \& Vasquez, 2014; Jitendra vd., 2002; Joseph \& Hunter, 2001; Maccini \& Ruhl, 2000; Scheuermann vd., 2009; Test \& Ellis, 2005; Van Garderen, 

MÜDAHALELERİ: KAPSAMLI ALANYAZIN İNCELENMESİ

2007). Ayrıca araştırmaların \%56'sı ( $n=5$ ) değerlendirmeden tam puan almıştır (Freeman-Green vd., 2015; Hunt \& Vasquez, 2014; Jitendra vd., 2002; Joseph \& Hunter, 2001; Test \& Ellis, 2005; Van Garderen, 2007).

\section{Dış Geçerlik}

İncelenen araştırmaların \%100'ü $(n=9)$ dış geçerlik bakımından yüksek kalite standartlarını karş1lamaktadır (Cass vd., 2003; Freeman-Green vd., 2015; Hunt \& Vasquez, 2014; Jitendra vd., 2002; Joseph \& Hunter, 2001; Maccini \& Ruhl, 2000; Scheuermann vd., 2009; Test \& Ellis, 2005; Van Garderen, 2007). Ayrica araştırmaların \%56'sı $(n=5)$ değerlendirmeden tam puan almıştır (Freeman-Green vd., 2015; Jitendra vd., 2002; Maccini \& Ruhl, 2000; Scheuermann vd., 2009; Van Garderen, 2007).

\section{Sosyal Geçerlik}

İncelenen araştırmaların \%44'ü $(n=4)$ sosyal geçerlik bakımından yüksek kalite standartlarını karşılamaktadır (Freeman-Green vd., 2015; Jitendra vd., 2002; Maccini \& Ruhl, 2000; Test \& Ellis, 2005). Araştırmaların \%56'sının $(n=5)$ bağımlı değişkenin sosyal önemi ve bağımsız değişken uygulamasının uygulama kolaylığ1 ve maliyet verimliliği maddelerinden 1 puan alarak kalite göstergelerini karşılamadığı görülmüştür (Cass vd., 2003; Hunt \& Vasquez, 2014; Joseph \& Hunter, 2001; Scheuermann vd., 2009; Van Garderen, 2007). Ayrica araştırmaların \%11'i $(n=1)$ değerlendirmeden tam puan almıştır (Jitendra vd., 2002).

Araştırmalar genel olarak değerlendirildiğinde, temel kalite göstergelerinin başlama düzeyi, deneysel kontrol/iç geçerlik ve dış geçerlik bileşenlerinde tüm çalışmalar belirlenen ölçütleri karşılamaktadır. Diğer bileşenler için \%44 $(n=4)$ ile \%78 $(n=7)$ arasında değişen orandaki çalışmanın, belirlenen ölçütleri karşıladığı görülmüştür. Sadece bir çalışmanın 21 maddeden oluşan kalite göstergelerinin tümünü karşıladığı görülmüştür (Jitendra vd., 2002).

\section{Kodlayıcılar Arası Güvenirlik Bulguları}

Betimsel analiz sürecinde kodlayıclar arası güvenirilik \%95 olarak hesaplanmıștır. Bu oranın hesaplanmasında en az \%89 en fazla \%100 değeri elde edilmiştir. Kalite göstergeleri analiz sürecinde ise kodlayıclar arası güvenirilik \%94 olarak hesaplanmıştır. Bu oranın hesaplanmasında en az \%82 en fazla \%100 değeri elde edilmiştir

\section{Tartışma}

Bu araştırmanın amacı, öğrenme güçlüğü olan ortaokul öğrencilerine yönelik 2000-2020 yılları arasında uygulanan matematik problem çözme müdahalelerini belirlemek ve araştırmaları kalite göstergeleri açısından inceleyerek ileri araştırmalara ve uygulamacılara yönelik bilgi sağlamaktır. İncelenen katılımcı makalelerin bulguları doğrultusunda üç temel sonuç üzerinde durulabilir. Sonuçlardan ilki, öğrenme güçlüğü olan öğrencilere yönelik uygulanan ve olumlu sonuçlar içeren çeşitli öğretim müdahaleleri bulunmaktadır. İkincisi, uygulanan müdahalelerin içerisindeki stratejiler öğrenme güçlüğü olan öğrencilerin problem çözme performanslarını geliştirmiştir. Son olarak, incelenen çalışmaların çoğunun temel kalite göstergelerinin bazı bileşenlerini karşıladığ belirlenmiştir. Kanıt temelli bir uygulamanın ortaya çıkabilmesi için kalite göstergelerini karşılayan daha fazla sayıda araştırmaya ihtiyaç vardır. Bu doğrultuda, öğrenme güçlüğü olan öğrencilerin problem çözme performanslarını desteklemeye yönelik daha fazla sayıda araştırma yürütülmesi gerekmektedir. Bu bölümde, betimsel analiz bulguları ve kalite göstergeleri bulguları başlıklandırılarak tartışılmıştır.

\section{Betimsel Analiz Bulgularının Tartışılması}

$\mathrm{Bu}$ araştırmada incelenen makalelerde, STAR (Maccini \& Ruhl, 2000), SOLVE (Freeman-Green vd., 2015) ve LAP (Test \& Ellis, 2005) gibi stratejilerin kullanıldığı, bu stratejilerin öğrencilere matematik problemlerini çözmede, problem çözme basamaklarını hatırlatmak amacıyla, strateji adında yer alan her bir harfin bir bilişsel strateji adımını işaret ettiği hatırlatıcılar yardımıyla öğretildiği görülmüştür. Genel olarak bu stratejiler, problemi analiz ederek okuma, anladıklarını kendilerine soru sorma yoluyla problemde verilenleri ayırt ederek açıklama, problemde istenilen bilginin ne olduğunu belirleme, problemi görselleştirme, problemin çözümüne götürecek planlamayı yapma, problemin çözümü için gereken hesaplamayı yapma, sonuca ulaşıldığında problemin çözüm süreçlerini kontrol etme gibi basamakları hatırlamada öğrencilere kolaylık sağlar (Maccini \& Ruhl, 2000). $\mathrm{Bu}$ stratejilerin içeriğindeki adımların birleştirilmiş şekilde uygulanmasının, öğrencilerin problem çözme sürecinde rol oynayan bilişsel stratejilerin ve bilişsel süreçlerin kullanmasında dolayısıyla doğru problem çözmede rolü olduğu düşünülmektedir (Montague, 1992). 
Bu araştırmada, öğrenme güçlüğü olan öğrencilerin problem çözme becerilerini desteklemede ele alınan bir diğer yaklaşım somut-yarı somut-soyut yaklaşımıdır (Hunt \& Vasquez, 2014). Öğrenme güçlüğü olan öğrencilerin gerçek nesneler içeren problemler üzerinden nicelikleri belirlemeleri ve bu nicelikler arasındaki ilişkileri grafik, tablo, şema, şekil ve formüllerle göstermeleri sağlanmalıdır. Soyut içerikli problemler temsil biçimleriyle somut düşünceden soyut düşünceye geçmede birer araç olarak nitelendirilmekte, bu durum öğrencilerin soyut semboller ile somut nesneler arasında bağ kurmalarını ve soyut yapıları kendilerinin oluşturmalarını sağlamaktadır (Tertemiz, 2017). Başka bir deyişle, etkili bir problem çözümü için öğrenciler matematiği seyrederek öğrenemezler. Öğrencinin çevresi ile doğrudan etkileşime girerek hem fiziksel hem de zihinsel olarak katılımı gerekmektedir. Öğrenciler, ancak belirtilen yolla -somut deneyimler sayesinde- kendi kavramlarını inşa edebilirler (Olkun \& Toluk, 2003). Bu doğrultuda, somut-yarı somut-soyut yaklaşımı sayesinde adım adım işlemler dizisi ile hesaplama becerilerini de gerektiren matematik problemleri çözülebilmektedir (Scheuermann vd., 2009). Öğrencilerin problemleri çözmek için, uygun bilgileri seçmeleri, doğru olarak seçilmiş işlemleri uygulamaları gerekmektedir (Strickland \& Maccini, 2013). Öğrenme güçlüğü olan öğrencilerin belirli bir strateji repertuarları olduğu, ancak uygun olan stratejilerin seçimi, organize edilmesi ve uygulanması alanlarında sınırlılıkları olduğu göz önüne alındığında (Sweeney, 2010), somut-yarı somut-soyut yaklaşımının problem çözümünde etkili olduğu belirtilmektedir (Hunt \& Vazquez, 2014). Alanyazında somut-yarı somut-soyut yaklaşımı kullanılarak öğrenme güçlüğü olan öğrencilere yönelik problem çözme müdahaleleri gerçekleştirilmiştir (Scheuermann vd., 2009; Strickland \& Maccini, 2013). Uygulanan müdahale, öğrenme güçlüğü olan öğrencilerin cebir, geometri, oran ve orantı konularında problem çözme performanslarını artırmıştır.

$\mathrm{Bu}$ araştırmada incelenen makalelerde uygulanan müdahalelerin öğrencilerin matematik problemi çözme becerileri üzerinde etkili olmasının nedenlerinden birinin müdahaleler içerisinde yer alan üstbilişsel stratejiler olduğu düşünülmektedir. Üstbilişsel stratejiler kendini gözlemleme, kendini değerlendirme, kendini kontrol etme, kendini izleme, kendine yönerge verme, kendine soru sorma süreçlerini içermekte ve bu stratejiler özellikle yeni veya zor bir görev ile karşılaşıldığında ortaya çıkmakta ve görevin tamamlanmasında faydalı olmaktadır (Lucangeli \& Cabrele, 2006). Bu bağlamda, öğrenme güçlüğü olan öğrenciler üstbilişsel stratejilere; matematik problem çözmede kullanılan bilişsel işlemleri düzenlenmek, bu işlemleri yönetmek ve kendi problem çözme performanslarını düzenlemek amacıyla başvurmaktadır (Montague, 1992). Bununla birlikte öğrenciler, stratejilerin uygulama şekillerini anlama, etkili stratejiler geliştirme ve bu süreçsel işlemleri yönetme bağlamında üstbilişsel stratejileri kullanabilmektedir (Lucangeli \& Cabrele, 2006). Nitekim, STAR stratejisinin birinci basamağında yer alan "Neleri biliyorum? Neleri bulmalıyım?" ve son basamağında yer alan "Sonuç bir anlam ifade ediyor mu? Neden?" soruları (Maccini \& Ruhl, 2000); LAP stratejisinin ilk basamağında yer alan "Ne yapmam gerekiyor?" (Test \& Ellis, 2005) ve "Bu sonuca nasıl ulaştım?" (Scheuermann vd., 2009) gibi sorular üstbilişsel stratejiler içerisinde yer alan kendine soru sorma stratejileridir. Kendine soru sorma, problemi ve çözüm basamaklarını düşünme olarak tanımlanmakta, bu stratejinin problem çözme sürecinde strateji bilgisi ve kullanımı için gerekli olduğu belirtilmektedir (Montague, 1992). Alanyazında öğrencilerin matematik performanslarını arttırmaya yönelik yapılan strateji öğretim çalışmalarında da kendine soru sorma stratejisine rastlanmaktadır (Karabulut \& Özmen, 2018; Montague, 1992; Sweeney, 2010). Böylece matematik problemi çözme sürecinde, bu araştırmada olduğu gibi kendine soru sorma stratejisi, öğrencilerin uygun stratejileri seçmelerine ve uygulamalarına yardımcı olmaktadır. Bu nedenle, kendine soru sormanın problem çözmede etkili sonuç elde edilmesinde büyük rolü olduğu düşünülmektedir.

$\mathrm{Bu}$ araştırmada incelenen makalelerde öğrencilerin matematik problemi çözme becerileri üzerinde etkili olmasının nedenlerinden bir diğerinin görselleștirme stratejisi olduğu düşünülmektedir (Jitendra vd., 2002; Van Garderen 2006). Nitekim alanyazında da bu veriyi destekleyecek araştırma bulguları mevcuttur (Gersten vd., 2009; Ives, 2007). Problem çözme modelini ilk defa ortaya atan Polya (1957), problem çözme sürecini başarılı bir şekilde tamamlayabilmek ve usta problem çözücü olarak nitelendirilmek için, kendi deneyimlerine dayalı öneriler listesi hazırlamış ve bu doğrultuda problem çözme sürecinde şekil çizmeyi ve problemi görselleştirmeyi önermiştir. Polya (1957), problemin bir geometri problemi olmasa da şekil çizmenin mümkün olduğunu, problemi görselleştirmenin çözüm için önemli bir aşama olduğunu ileri sürmüştür. Yapılan araştırmalarda görselleştirme stratejilerinin hem özel gereksinimli olan hem de normal gelişim gösteren akranlarının problem çözme becerilerini geliştirdiği bulunmuştur (Ives, 2007; Van Garderen, 2007). Öğrencilerin çalışan bellek ve problem çözme adımlarını koordine etme ile ilişkili yaşadıkları güçlükler nedeniyle problem içerisinde yer alan bilgilerin düzenlenerek sunumunu sağlayan görsel stratejiler, problem çözümünde büyük fayda sağlamaktadır (Geary, 2004). Bu doğrultuda kullanılan şematik düzenleyiciler ve diğer görsel destekler (resim, çizim vb.), öğrencilerin problem içerisinde yer alan farklı bilgileri bir araya getirerek problemi anlama düzeylerini arttırabilmektedir (Ives, 2007; Van Garderen, 2007). Öğrencilerin problemleri şematik düzenleyiciye yerleştirmeleri, problemi anlamaları 
ve doğru çözmeleri için yol göstermektedir (Ives, 2007; Van Garderen, 2007). Ayrıca, bu durum bilginin depolanmasını sağlamaktadır. Böylece çalışan belleğe destek olduğu için bilginin işlenmesini hızlandırdığı belirtilmektedir (Keeler \& Swanson, 2001). Görselleştirme stratejisinin yer aldığı öğretim programlarının uygulanması ile öğrenme güçlüğü olan öğrencilerin problem çözme sürecinde kullandıkları şema sayılarının arttığı, şemaları kullanım düzeylerinin geliştiği, şema kullanımını farklı problemlere genelledikleri (Van Garderen, 2007) ve problemlerin çözümünde daha iyi performans sergiledikleri bulunmuştur (Jitendra vd., 2002). Görselleştirme, öğrencinin dikkatini probleme çekmede, öğrencinin var olan bilgilerini organize etmesinde ve problemde yer alan somut ifadeler ile soyut ifadelerinin ilişkilendirilmesinde yararlı bir strateji olarak karşımıza çıkmaktadır (Ives, 2007; Karabulut \& Özmen, 2018). Bunun için görselleştirmenin matematik problemi çözmede kullanılması matematik eğitimine yeni bir boyut kazandırabilir.

Öğrenme güçlüğü olan bazı öğrenciler kendi düşünme süreçlerini organize etme gereksinimindedirler (Krawec vd., 2013; Montague vd., 2011; Montague vd., 2014). Bu öğrenciler sesli düşünme protokolü süreçlerinden faydalanarak problem çözmeye ilişkin planlarını sözlü olarak yaparak çözüme gitmektedirler (Rosenzweig vd., 2011). Bu araştırmada incelenen bazı makalelerde de (Maccini \& Ruhl, 2000; Scheuermann vd., 2009) sesli düşünme protokolleri kullanılmıştır. Böylece uygulamacılar tarafindan doğrudan gözlemlenmesi güç olan bilgiler için veri toplanmıştır. Bu veriler sayesinde uygulayıcılar öğrencilerin problem çözme süreçlerinde kullandıkları stratejileri gözlemleme ve problem çözme sürecinde yaptıkları farklı hata türlerine ilişkin bilgi sahibi olabilmektedir (Rosenzweig vd., 2011). Böylece, öğrenme güçlüğü olan öğrencilerin ihtiyaç duydukları problem çözme becerilerine yönelik müdahale programlarının oluşturulmasında bu verilerden faydalanılarak öğrenci profilleri oluşturulmasında kullanılabilmektedir. Bu öğrencilerin ihtiyaçları doğrultusunda kendine soru sorma, kendine yönerge verme ve kendini izleme gibi üstbilişsel stratejilerden oluşan öğretim programları hazırlanabilmektedir (Montague, 1992).

$\mathrm{Bu}$ araştırmada incelenen makalelerde öğrencilerin problem çözme performanslarının arttırılmasında etkili olan değişkenlerden birinin araştırmaların hepsinde kullanılan destekleyiciler ve yapılandırılmış çalışma kağıtları olduğu düşünülmektedir (Cass vd., 2003; Freeman-Green vd., 2015; Hunt \& Vasquez, 2014; Jitendra vd., 2002; Joseph \& Hunter, 2001; Maccini \& Ruhl, 2000; Scheuermann vd., 2009; Test \& Ellis, 2005; Van Garderen, 2007). Bu bağlamda, Marshall (1995) problem çözme öğretiminde kullanılan destekleyicilerin problem çözerken problemdeki durumun tanınmasını ve uygun işlemin seçilmesini kolaylaştırdığını belirtmektedir.

\section{Kalite Göstergeleri Bulgularının Tartışılması}

$\mathrm{Bu}$ araştırmada incelenen makalelerde, Horner ve diğerlerinin (2005) belirlediği yedi kalite göstergesinin tamamını sadece bir çalışmanın karşıladığı görülmüsstür (Jitendra vd., 2002). Üç çalışma yedi göstergenin altısı için kabul edilebilir kanıt sağlamaktadır (Freeman-Green vd., 2015; Hunt \& Vasquez, 2014; Maccini \& Ruhl, 2000). Dört çalışma yedi göstergenin beşi için kabul edilebilir kanıt sağlamaktadır (Cass vd., 2003; Scheuermann vd., 2009; Test \& Ellis, 2005; Van Garderen, 2007). Geriye kalan bir çalışma ise yedi göstergenin dördü için kabul edilebilir kanıt sağlamaktadır (Joseph \& Hunter, 2011). Bu bulgular, Aydın ve Tekin-İftar (2019), Jitendra ve diğerlerinin (2011) ve Jitendra ve diğerlerinin (2013) yaptığı araştırma bulgularıyla genel olarak tutarlılık göstermektedir.

$\mathrm{Bu}$ araştırmanın bulgularına göre temel kalite göstergelerinin başlama düzeyi, deneysel kontrol/iç geçerlik ve dış geçerlik bileşenlerinde incelenen makalelerin tümünün belirlenen ölçütleri karşıladığı, katılımcılar ve ortam, bağımlı değişken, bağımsız değişken, sosyal geçerlik bileşenlerinde ise bazı çalışmaların belirlenen ölçütleri karşılamadığı görülmüştür. Jitendra ve diğerlerinin (2013) yaptığı araştırmada temel kalite göstergelerinin katılımcılar ve ortam bileşeninde $\% 70(n=7)$, bağımlı değişken bileşeninde $\% 70(n=7)$, bağımsız değişken bileşeninde $\% 70(n=7)$, başlama düzeyi bileşeninde $\% 70(n=7)$, deneysel kontrol/iç geçerlik bileşeninde $\% 40$ $(n=4)$, dış geçerlik bileşeninde $\% 100(n=10)$, sosyal geçerlik bileşeninde $\% 50(n=5)$ oranında çalışma belirlenen ölçütleri karşılamaktadır. Jitendra ve diğerlerinin (2013) incelediği çalışmalar, 1993-2011 yıllarına ve bu çalışmaların \%40'ı $(n=4) 2000$ 'ten önceki yıllara aittir. Jitendra ve diğerlerinin (2011) araştırmasına dahil edilen çalışmalar ise daha önceki yıllara aittir ve kalite göstergelerini karşılama bakımından benzer bir durum görülmüştür. Yapılan bu araştırmada incelenen çalışmalar ise 2000-2015 yıllarına ve bu çalışmaların \%56'sı ( $n=$ 5) 2005 ve sonrasına aittir. Horner ve diğerleri tek denekli çalışmalar için kalite göstergelerini 2005 yılında belirlemiştir. $\mathrm{Bu}$ durum göz önünde bulundurulduğunda incelenen çalışmaların yapıldığı yıllar arasındaki farklı1ıklar, çalışmalarda bulunması gereken kalite göstergelerini de etkilemiş olabilir. Aradaki farklılı̆̆ın bu nedenden kaynaklandığı düşünülmektedir. Bundan sonra yapılacak olan çalışmaların kalite göstergeleri dikkate alınarak planlanması, araştırmaların kalite düzeyinin arttırılmasını ve araştırmalardaki uygulamaların etkisinin 
nesnel bir şekilde görülmesini sağlayabilir. Sonuç olarak bu durum kanıt temelli uygulamaların ortaya çıkmasına zemin hazırlayabilir (Odom vd., 2005).

$\mathrm{Bu}$ araştırmada birtakım sınırlılıklar bulunmaktadır. Araştırma kapsamında hakemli dergilerde yayınlanmış tek denekli çalışmaları içeren makaleler incelemeye alınmıştır. Grup deneysel çalışmalar, lisansüstü tezler, araştırma raporları vb. yayınlar değerlendirmeye dahil edilmemiş̧ir. Ulaşılan çalışmalar, dahil etme kriterleri doğrultusunda belirlenen arama motorlarının sonuçlarıyla sınırıdır. Arama motorlarında çıkmayan çalışmaların değerlendirmeye dahil edilmemiş olma ihtimali vardır. Bu araştırma kapsamında öğrenme güçlügü olan öğrencilere yönelik uygulanan matematik problemi çözme müdahalelerinin incelenmesi amaçlanmıştır. Öğrenme güçlüğünün matematik, okuma ve yazma güçlüğü gibi alt türleri bulunmaktadır. Bu alt türlere yönelik uygulanan müdahalelerin farklılık gösterebileceği düşülmektedir. Ancak incelenen çalışmalarda belirtilmediği için öğrenme güçlüğünün alt türlerine yönelik inceleme yapılmamıştır. Horner ve diğerleri, tek denekli araştırmalar için kalite göstergelerini 2005 yılında belirlemiştir. Her geçen gün tek denekli araştırma yöntemlerinin uygulama kriterleri güncellenebilmektedir. Örneğin, ilk başlarda başlama düzeyinden uygulama düzeyine geçmek için en az üç veri noktasının kararlılık göstermesi beklenirken günümüzde bazı araştırmacılar üç veri noktasını yeterli görmemektedir. Bu gerekçeyle 2005 yılında belirlenen kalite göstergeleri üzerinden değerlendirme yapılması bir sınırlılık olarak değerlendirilebilir.

Araştırma bulgularına dayalı olarak eğitime, uygulamaya ve ileri araştırmalara yönelik öneriler bulunmaktadır. Alanyazın öğrenme güçlüğü olan öğrencilerin uygun müdahalelerle desteklendiğinde matematik problem çözümünde başarıya ulaş̧ıklarını göstermektedir. Bu doğrultuda, öğrenme güçlüğü olan öğrenciler ile çalışan uzmanların, problem çözme aşamaları, şematik düzenleyiciler, bilişsel ve üstbilişsel stratejiler ile sesli düşünme protokolleri gibi öğrencilerin başarılı bir şekilde problem çözümünü kolaylaştıracak stratejileri içeren müdahale programları oluşturması faydalı olacaktır. Türkiye'de öğrenme güçlüğü olan ortaokul öğrencilerine matematik problemi çözmede bilişsel ve üstbilişsel stratejilerin öğretimi, şematik düzenleyicilerin kullanımı, problem temelli öğretim gibi yaklaşımları içeren, herhangi bir öğretim yönteminin veya müdahale stratejisinin incelendiği çalışmaya rastlanmamış olması nedeniyle bu araştırmanın bulgularının ilerideki ulusal alanyazında yapılacak olan öğretim çalışmalarına temel oluşturması ve hazırlanacak müdahale programlarına 1şık tutması beklenmektedir.

\section{Yazarların Katkı Düzeyleri}

Yazarlar, çalışma konusunu belirleme, araştırma deseni, veri toplama, verilerin analizi ve çalışmanın raporlanması görevlerini iş birliği içerisinde gerçekleştirmişlerdir. 


\section{Kaynaklar}

Aydın, O., \& Tekin-İftar, E. (2019). Otizm spektrum bozukluğu olan bireylere matematik becerilerini öğretimi: Tek-denekli araştırmalarda betimsel ve meta analiz [Teaching math skills to individuals with autism spectrum disorder: a descriptive and meta-analysis in single case research designs]. Ankara Üniversitesi Ĕgitim Bilimleri Fakültesi Özel Eğitim Dergisi, 21(2), 383-426. https://doi.org/10.21565/ozelegitimdergisi.521232

Aydın, O., Tekin-İftar, E., \& Rakap, S. (2019). Bilimsel-dayanaklı uygulamaları belirlemede “tek-denekli deneysel araştırmaların niteliksel göstergeleri” yönergesinin matematik becerileri öğretimi örneğinde ele alınışı [Explanation of "quality indicators of single-subject experimental research studies" rubric using studies focused on teaching mathematics skills]. Ankara Üniversitesi Ĕ̈itim Bilimleri Fakültesi Özel Eğitim Dergisi, 20(3), 597-628. https://doi.org/10.21565/ozelegitimdergisi.421952

Baki, K. (2014). Şemaya dayalı öğretim stratejisinin zihinsel yetersizliği olan öğrencilerin matematikte sözel problem çözme becerilerine etkililiği [The effects of schema-based strategy instruction on the mathematical word problem solving skills of students with intellectual disabilty] (Tez Numaras1: 375309) [Yüksek lisans tezi, Anadolu Üniversitesi]. Yükseköğretim Kurulu Ulusal Tez Merkezi.

Bottge, B. A., \& Cho, S. J. (2013). Effects of enhanced anchored instruction on skills aligned to common core math standards. Learning Disabilities: A Multidisciplinary Journal, 19(2), 73-83. https://doi.org/10.18666/LDMJ-2013-V19-I2-4796

Bottge, B. A., Grant, T. S., Stephens, A. C., \& Rueda, E. (2010). Advancing the math skills of middle school students in technology education classrooms. NASSP Bulletin, 94(2), 81-106. https://doi.org/10.1177/0192636510379902

Bottge, B. A., Heinrichs, M., Chan, S., \& Serlin, R. C. (2001). Anchoring adolescents' understanding of math concepts in rich problem solving environments. Remedial and Special Education, 22(5), 299-314. https://doi.org/10.1177/074193250102200505

Bottge, B. A., Heinrichs, M., Chan, S., Mehta, Z. D., \& Watson, E. (2003). Effects of video-based and applied problems on the procedural math skills of average- and low-achieving adolescents. Journal of Special Education Technology, 18(2), 5-22. https://doi.org/10.1177/016264340301800201

Bottge, B. A., Heinrichs, M., Mehta, Z. D., \& Hung, Y. H. (2002). Weighing the benefits of anchored math instruction for students with disabilities in general education classes. The Journal of Special Education, 35(4), 186-200. https://doi.org/10.1177/002246690203500401

Bottge, B. A., Ma, X., Gassaway, L., Toland, M. D., Butler, M., \& Cho, S. J. (2014). Effects of blended instructional models on math performance. Exceptional Children, 80(4), 423-437. https://doi.org/10.1177/0014402914527240

Bottge, B. A., Rueda, E., Grant, T. S., Stephens, A. C., \& Laroque, P. T. (2010). Anchoring problem-solving and computation instruction in context-rich learning environments. Exceptional Children, 76(4), 417-437. https://doi.org/10.1177/001440291007600403

Bottge, B. A., Rueda, E., LaRoque, P. T., Serlin, R. C., \& Kwon, J. (2007). Integrating reform-oriented math instruction in special education settings. Learning Disabilities Research \& Practice, 22(2), 96-109. https://doi.org/10.1111/j.1540-5826.2007.00234.X

Bottge, B. A., Rueda, E., Serlin, R. C., Hung, Y. H., \& Kwon, J. M. (2007). Shrinking achievement differences with anchored math problems challenges and possibilities. The Journal of Special Education, 41(1), 3149. https://doi.org/10.1177/00224669070410010301

Bryant, D. P., Bryant, B. R., \& Hammill, D. D. (2000). Characteristic behaviors of students with LD who have teacher-identified math weaknesses. Journal of Learning Disabilities, 33(2), 168-177. https://doi.org/10.1177/002221940003300205

Busk, P. L., \& Serlin, R. C. (1992). Meta-analysis for single-case research. In T. Kratochwill \& J. Levin (Eds.), Single case research design and analysis (1st ed., pp. 187-212). Routledge. 
Butler, F. M., Miller, S. P., Crehan, K., Babbitt, B., \& Pierce, T. (2003). Fraction instruction for students with mathematics disabilities: Comparing two teaching sequences. Learning Disabilities Research \& Practice, 18(2), 99-111. https://doi.org/10.1111/1540-5826.00066

Calhoon, M. B., \& Fuchs, L. S. (2003). The effects of peer-assisted learning strategies and curriculum-based measurement on the mathematics performance of secondary students with disabilities. Remedial and Special Education, 24(4), 235-245. https://doi.org/10.1177/07419325030240040601

Carpenter, T. P., Ansell, E., Franke, M. L., Fennema, E., \& Weisbeck, L. (1993). Models of problem solving: A study of kindergarten children's problem-solving processes. Journal for Research in Mathematics Education, 24(5), 428- 441. https://doi.org/441.10.2307/749152

${ }^{*}$ Cass, M., Cates, D., Smith, M., \& Jackson, C. (2003). Effects of manipulative instruction on solving area and perimeter problems by students with learning disabilities. Learning Disabilities Research \& Practice, 18(2), 112-120. https://doi.org/10.1111/1540-5826.00067

Cawley, J. F., \& Miller, J. H. (1986). Selected views on metacognition, arithmetic problem solving, and learning disabilities. Learning Disabilities Focus, 2(1), 36-48.

Cook, B. G., Collins, L. W., Cook, S. C., \& Cook, L. (2019). Evidence-based reviews: How evidence based practices are systematically identified. Learning Disabilities Research \& Practice, 35(1), 6-13. https://doi.org/10.1111/ldrp.12213

Eldeniz-Çetin, M., Çay, E., \& Bozak, B. (2020). Çoklu yetersizliği olan bireylerle yapılmış tek denekli araştırmaların incelenmesi: Sistematik derleme. Ankara Üniversitesi Eğitim Bilimleri Fakültesi Özel Eğitim Dergisi, 21(2) , 357-381. https://doi.org/10.21565/ozelegitimdergisi.521556

Foegen, A. (2008). Algebra progress monitoring and interventions for students with learning disabilities. Learning Disability Quarterly, 31(2), 65-78. https://doi.org/10.2307/20528818

Fuchs, D., Fuchs, L., Mathes, P., \& Lipsey, M. (2000). Reading differences between low-achieving students with and without learning disabilities: A meta-analysis. In R. Gersten, E. P. Schiller, \& S. R. Vaughn (Eds.), Contemporary special education research (1st ed., pp. 81-105). Routledge.

Fuchs, L. S., Fuchs, D., \& Prentice, K. (2004). Responsiveness to mathematical problem-solving instruction: Comparing students at risk of mathematics disability with and without risk of reading disability. Journal of Learning Disabilities, 37(4), 293-306. https://doi.org/10.1177/00222194040370040201

*Freeman-Green, S. M., O'Brien, C., Wood, C. L., \& Hitt, S. B. (2015). Effects of the SOLVE strategy on the mathematical problem solving skills of secondary students with learning disabilities. Learning Disabilities Research \& Practice, 30(2), 76-90. https://doi.org/10.1111/ldrp.12054

Geary, D. C. (2004). Mathematics and learning disabilities. Journal of Learning Disabilities, 37(1), 4-15. https://doi.org/10.1177/00222194040370010201

Gersten, R., Chard, D. J., Jayanthi, M., Baker, S. K., Morphy, P., \& Flojo, J. (2009). Mathematics instrucoction for students with learning disabilities: A meta-analysis of instructional components. Review of Educational Research, 79(3), 1202-1242. https://doi.org/10.3102/0034654309334431

Goldman, S. R. (1989). Strategy instruction in mathematics. Learning Disability Quarterly, 12(1), 43-55. https://doi.org/10.2307/1510251

Guerin, G., \& Male, M. C. (2006). Learning difficulties and teaching strategies. In G. Guerin \& M. C. Male (Eds.), Addressing learning disabilities and difficulties: How to reach and teach every student (2nd ed., pp. 1366). Corwin.

Hamilton, C., \& Shinn, M. R. (2003). Characteristics of word callers: An investigation of the accuracy of teachers' judgments of reading comprehension and oral reading skills. School Psychology Review, 32(2), 228-240. https://doi.org/10.1080/02796015.2003.12086195

House, A. W., House, B. G., \& Campbell, M. B. (1981). Measures of interobserver agreement: Calculation formula and distribution effect. Journal of Behavioral Assessment, 3(1), 37-57. https://doi.org/10.1007/BF01321350 

MÜDAHALELERİ: KAPSAMLI ALANYAZIN İNCELENMESİ

Horner, R. H., Carr, E. G., Halle, J., McGee, G., Odom, S., \& Wolery, M. (2005). The use of single-subject research to identify evidence-based practice in special education. Exceptional Children, 71(2), 165-179. https://doi.org/10.1177/001440290507100203

*Hunt, J. H., \& Vasquez, E. (2014). Effects of ratio strategies intervention on knowledge of ratio equivalence for students with learning disability. The Journal of Special Education, 48(3), 180-190. https://doi.org/10.1177/0022466912474102

Hutchinson, N. L. (1993). Effects of cognitive strategy instruction on algebra problem solving of adolescents with learning disabilities. Learning Disability Quarterly, 16(1), 34-63. https://doi.org/10.2307/1511158

Iseman, J. S., \& Naglieri, J. A. (2011). A cognitive strategy instruction to improve math calculation for children with ADHD and LD: A randomized controlled study. Journal of Learning Disabilities, 44(2), 184-195. https://doi.org/10.1177/0022219410391190

Ives, B. (2007). Graphic organizers applied to secondary algebra instruction for students with learning disorders. Learning Disabilities Research \& Practice, 22(2), 110-118. https://doi.org/10.1111/j.15405826.2007.00235.x

*Jitendra, A., DiPipi, C. M., \& Perron-Jones, N. (2002). An exploratory study of schema-basedword-problem solving instruction for middle school students with learning disabilities: An emphasis on conceptual and procedural understanding. The Journal of Special Education, 36(1), 23-38. https://doi.org/10.1177/00224669020360010301

Jitendra, A. K., \& Hoff, K. (1996). The effects of schema-based instruction on the mathematical word-problemsolving performance of students with learning disabilities. Journal of Learning Disabilities, 29(4), 422431. https://doi.org/10.1177/002221949602900410

Jitendra, A. K., Griffin, C. C., Haria, P., Leh, J., Adams, A., \& Kaduvettoor, A. (2007). A comparison of single and multiple strategy instruction on third-grade students' mathematical problem solving. Journal of Educational Psychology, 99(1), 115-127. https://doi.org/10.1037/0022-0663.99.1.115

Jitendra, A. K., Petersen-Brown, S., Lein, A. E., Zaslofsky, A. F., Kunkel, A. K., Jung, P. G., \& Egan, A. M. (2013). Teaching mathematical word problem solving: The quality of evidence for strategy instruction priming the problem structure. Journal of Learning Disabilities, 48(1), 51-72. https://doi.org/10.1177/0022219413487408

Jitendra, A., Burgess, C., \& Gajria, M. (2011). Cognitive strategy instruction for improving expository text comprehension of students with learning disabilities: The quality of evidence. Exceptional Children, 77(2), 135-159. https://doi.org/10.1177/001440291107700201

Jonassen, D. (2003). Using cognitive tools to represent problems. Journal of research on Technology in Education, 35(3), 362-381. https://doi.org/10.1080/15391523.2003.10782391

*Joseph, L. M., \& Hunter, A. D. (2001). Differential application of a cue card strategy for solving fraction problems: Exploring instructional utility of the cognitive assessment team. Child Study Journal, 31(2), 123-136. https://www.jstor.org/stable/42899825

Karabulut, A., \& Özmen, E. R. (2018). Effect of "Understand and Solve!" strategy instruction on mathematical problem solving of students with mild intellectual disabilities. International Electronic Journal of Elementary Education, 11(2), 77-90. https://doi.org/10.26822/iejee.2018245314

Karabulut, A., Yıkmış, A., Özak, H., \& Karabulut, H. (2015). Şemaya dayalı problem çözme stratejisinin zihinsel yetersizliği olan öğrencilerin problem çözme performanslarına etkisi. Abant İzet Baysal Üniversitesi Eğitim Fakültesi Dergisi, 15(Özel Say1), 243-258. https://doi.org/10.17240/aibuefd.2015.15.05000128657

Karakoç, T. (2002). Görme engelli ögrrencilere matematikte sözlü problem çözümünün öğretiminde doğrudan ögretim yaklaşımına göre hazırlanan öğretim programının akranlar aracılı̆̆ılla sunulmasının etkililiğ $i$ [The effectiveness of curriculum prepared direct teaching approach to teaching visually impaired students in the solution of word problem in mathematics through peers] (Tez Numaras1: 113248) [Yüksek lisans tezi, Gazi Üniversitesi]. Yükseköğretim Kurulu Ulusal Tez Merkezi. 

MÜDAHALELERİ: KAPSAMLI ALANYAZIN İNCELENMESİ

Keeler, M. L., \& Swanson, H. L. (2001). Does strategy knowledge influence working memory in children with mathematical disabilities? Journal of Learning Disabilities, 34(5), 418-434. https://doi.org/10.1177/002221940103400504

Kingsdorf, S., \& Krawec, J. (2014). Error analysis of mathematical word problem solving across students with and without learning disabilities. Learning Disabilities Research \& Practice, 29(2), 66-74. https://doi.org/10.1111/ldrp.12029

Kot, M., \& Yıkmış, A. (2018). The effects of schema-based instruction on the mathematical problem solving skills of children with mental retardation. Journal of Kalem Education and Human Sciences, 8(2), 335-358. https://doi.org/10.23863/kalem.2019.107

Kratochwill, T. R., \& Stoiber, K. C. (2002). Evidence-based interventions in school psychology: Conceptual foundations of the procedural and coding manual of division 16 and the society for the study of school psychology task force. School Psychology Quarterly, 17(4), 341-389. https://doi.org/10.1521/scpq.17.4.341.20872

Krawec, J., Huang, J., Montague, M., Kressler, B., \& de Alba, A. M. (2013). The effects of cognitive strategy instruction on knowledge of math problem-solving processes of middle school students with learning disabilities. Learning Disability Quarterly, 36(2), 80-92. https://doi.org/10.1177/0731948712463368

Lee, J., Bryant, D. P., Ok, M. W., \& Shin, M. (2020). A systematic review of interventions for algebraic concepts and skills of secondary students with learning disabilities. Learning Disabilities Research \& Practice, 35(2), 89-99. https://doi.org/10.1111/ldrp.12217

Lucangeli, D., \& Cabrele, S. (2006). Mathematical difficulties and ADHD. Exceptionality, 14(1), 53-62. https://doi.org/10.1207/s15327035ex1401_5

Maccini, P., \& Hughes, C. A. (1997). Mathematics interventions for adolescents with learning disabilities. Learning Disabilities Research and Practice, 12(3), 168-76.

Maccini, P., \& Hughes, C. A. (2000). Effects of a problem-solving strategy on the introductory algebra performance of secondary students with learning disabilities. Learning Disabilities Research \& Practice, 15(1), 10-21. https://doi.org/10.1207/SLDRP1501_2

Maccini, P., Mulcahy, C. A., \& Wilson, M. G. (2007). A follow up of mathematics interventions for secondary students with learning disabilities. Learning Disabilities Research \& Practice, 22(1), 58-74. https://doi.org/10.1111/j.1540-5826.2007.00231.x

*Maccini, P., \& Ruhl, K. L. (2000). Effects of graduated instructional sequence on the algebraic subtraction of integers by secondary students with disabilities. Education and Treatment of Children, 23(4), 465-489. https://www.jstor.org/stable/42899634

Manalo, E., Bunnell, J. K., \& Stillman, J. A. (2000). The use of process mnemonics in teaching students with mathematics learning disabilities. Learning Disability Quarterly, 23(2), 137-156. https://doi.org/10.2307/1511142

Marita, S., \& Hord, C. (2017). Review of mathematics interventions for secondary students with learning disabilities. Learning Disability Quarterly, 40(1), 29-40. https://doi.org/10.1177/0731948716657495

Marshall, S. P. (1995). Schemas in problem solving. Cambridge University Press.

McGilly, K., \& Siegler, R. S. (1989). How children choose among serial recall strategies. Child Development, 60(1), 172-182. https://doi.org/10.2307/1131083

Miller, S. P., \& Hudson, P. J. (2007). Using evidence-based practices to build mathematics competence related to conceptual, procedural, and declarative knowledge. Learning Disabilities Research \& Practice, 22(1), 47-57. https://doi.org/10.1111/j.1540-5826.2007.00230.x

Miller, S. P., \& Mercer, C. D. (1997). Educational aspects of mathematics disabilities. Journal of Learning Disabilities, 30(1), 47-56. https://doi.org/10.1177/002221949703000104 

MÜDAHALELERİ: KAPSAMLI ALANYAZIN İNCELENMESİ

Moher, D., Liberati, A., Tetzlaff, J., \& Altman, D. G. (2009). Preferred reporting items for systematic reviews and meta-analyses: the PRISMA statement. Annals of Internal Medicine, 151(4), 264-269. https://doi.org/10.1371/journal.pmed.1000097

Montague, M. (1992). The effects of cognitive and metacognitive strategy instruction on the mathematical problem solving of middle school students with learning disabilities. Journal of Learning Disabilities, 25(4), 230248. https://doi.org/10.1177/002221949202500404

Montague, M. (1997). Student perception, mathematical problem solving, and learning disabilities. Remedial and Special Education, 18(1), 46-53. https://doi.org/10.1177/074193259701800108

Montague, M. (2007). Self-regulation and mathematics instruction. Learning Disabilities Research \& Practice, 22(1), 75-83. https://doi.org/10.1111/j.1540-5826.2007.00232.x

Montague, M. (2008). Self-regulation strategies to improve mathematical problem solving for students with learning disabilities. Learning Disability Quarterly, 31(1), 37-44. https://doi.org/10.2307/30035524

Montague, M., Enders, C., \& Dietz, S. (2011). Effects of cognitive strategy instruction on math problem solving of middle school students with learning disabilities. Learning Disabilities Quarterly, 34(4), 262-272. https://doi.org/10.1177/0731948711421762

Montague, M., Krawec, J., Enders, C., \& Dietz, S. (2014). The effects of cognitive strategy instruction on math problem solving of middle-school students of varying ability. Journal of Educational Psychology, 106(2), 469-481. https://doi.org/10.1037/a0035176

Morin, L. L., Watson, S. M., Hester, P., \& Raver, S. (2017). The use of a bar model drawing to teach word problem solving to students with mathematics difficulties. Learning Disability Quarterly, 40(2), 91-104. https://doi.org/10.1177/0731948717690116

Myers, J. A., Brownell, M. T., \& Gagnon, J. C. (2015). Mathematics interventions for students with learning disabilities (LD) in secondary school: A review of the literature. Learning Disabilities: A Contemporary Journal, 13(2), 207-235.

Naglieri, J. A., \& Johnson, D. (2000). Effectiveness of a cognitive strategy intervention in improving arithmetic computation based on the PASS theory. Journal of Learning Disabilities, 33(6), 591-597. https://doi.org/10.1177/002221940003300607

Odom, S. L., Brantlinger, E., Gersten, R., Horner, R. H., Thompson, B., \& Harris, K. R. (2005). Research in special education: Scientific methods and evidence-based practices. Exceptional Children, 71(2), 137-148. https://doi.org/10.1177/001440290507100201

Olkun, S., \& Toluk, Z. (2003). Illköğretimde etkinlik temelli matematik öğretimi [Activity based mathematics teaching in primary education]. Anı Yayınc1l1k.

Özkubat, U. (2019). Öğrenme güçlüğ̈̈ olan öğrenciler ile düşük ve ortalama başarılı olan öğrencilerin matematik problemi çözerken kullandıkları bilişsel stratejiler ile üstbilişsel işlevler arasındaki ilişkilerin incelenmesi [An examination of the relationships between cognitive strategies and metacognitive functions used during mathematical problem solving by the students with learning disabilities, low achieving, and average achieving] (Tez Numaras1: 602277) [Doktora tezi, Gazi Üniversitesi]. Yükseköğretim Kurulu Ulusal Tez Merkezi.

Özkubat, U., \& Özmen, E. R. (2018). Öğrenme güçlüğü olan öğrencilerin matematik problemi çözme süreçlerinin incelenmesi: Sesli düşünme protokolü uygulaması [Analysis of mathematical problem solving process of students with learning disability: Implementation of think aloud protocol]. Ankara Üniversitesi Ĕ̈itim Bilimleri Fakültesi Ö̈zel Eğitim https://doi.org/10.21565/ozelegitimdergisi.299494

Özkubat, U., Karabulut, A., \& Özmen, E. R. (2020). Mathematical problem-solving processes of students with special needs: A cognitive strategy instruction model 'Solve It!'. International Electronic Journal of Elementary Education, 12(5), 405-416. https://doi.org/10.26822/iejee.2020562131

Polya, G. (1957). How to solve it. Doubleday. 

MÜDAHALELERİ: KAPSAMLI ALANYAZIN İNCELENMESİ

Reid, R., \& Lienemann, T. O. (2006). Self-regulated strategy development for students with learning disabilities. Teacher Education and Special Education, 29(1), 3-11. https://doi.org/10.1177/088840640602900102

Rivera, D. P. (1997). Mathematics education and students with learning disabilities: Introduction to the special series. Journal of Learning Disabilities, 30(1), 2-19. https://doi.org/10.1177/002221949703000101

Rozenzweig, C., Krawec, J., \& Montague, M. (2011). Metacognitive strategy use of eighth-grade students with and without learning disabilities during mathematical problem solving: A think-aloud analysis. Journal of Learning Disabilities, 44(6), 508-520. https://doi.org/10.1177/0022219410378445

Satsangi, R., \& Bouck, E. C. (2015). Using virtual manipulative instruction to teach the concepts of area and perimeter to secondary students with learning disabilities. Learning Disability Quarterly, 38(3), 174-186. https://doi.org/10.1177/0731948714550101

Satsangi, R., Bouck, E. C., Taber-Doughty, T., Bofferding, L., \& Roberts, C. A. (2016). Comparing the effectiveness of virtual and concrete manipulatives to teach algebra to secondary students with learning disabilities. Learning Disability Quarterly, 39(4), 240-253. https://doi.org/10.1177/0731948716649754

Satsangi, R., Hammer, R., \& Evmenova, A. S. (2018). Teaching multistep equations with virtual manipulatives to secondary students with learning disabilities. Learning Disabilities Research \& Practice, 33(2), 99-111. https://doi.org/10.1111/ldrp.12166

Scarlato, M. C., \& Burr,W. A. (2002). Teaching fractions to middle school students. Journal of Direct Instruction, 2(1), 23-38.

*Scheuermann, A. M., Deshler, D. D., \& Schumaker, J. B. (2009). The effects of the explicit inquiry routine on the performance of students with learning disabilities on one-variable equations. Learning Disability Quarterly, 32(2), 103-120. https://doi.org/10.2307/27740360

Schurter, W. A. (2002). Comprehension monitoring: An aid to mathematical problem solving. Journal of Developmental Education, 26(2), 22-33.

Sharp, E., \& Dennis, M. S. (2017). Model drawing strategy for fraction word problem solving of fourth-grade students with learning disabilities. Remedial and Special Education, 38(3) 181-192. https://doi.org/10.1177/0741932516678823

Simmerman, S., \& Swanson, H. L. (2001). Treatment outcomes for students with learning disabilities: How important are internal and external validity? Journal of Learning Disabilities, 34(3), 221-236. https://doi.org/10.1177/002221940103400303

Stanford, G., \& Oakland, T. (2000). Cognitive deficits underlying learning disabilities: Research perspectives from the United States. School Psychology International, 21(3), 306-321. https://doi.org/10.1177/0143034300213007

Strickland, T. K., \& Maccini, P. (2013). The effects of the concrete-representationalabstract-integration strategy on the ability of students with learning disabilities to multiply linear expressions within area problems. Remedial and Special Education, 34(3), 142-153. https://doi.org/10.1177/0741932512441712

Sweeney, C. M. (2010). The metacognitive functioning of middle school students with and without learning disabilities during mathematical problem solving. [Doctoral dissertation, University of Miami]. ProQuest Dissertations and Theses Global.

Tankersley, M., Cook, B. G., \& Cook, L. (2008). A preliminary examination to identify the presence of quality indicators in single-subject research. Education and Treatment of Children, 31(4), 523-548. https://www.jstor.org/stable/42899994

Tertemiz, N. I. (2017). İlkokul öğrencilerinin dört işlem becerisine dayalı kurdukları problemlerin incelenmesi [Examining the problems that primary school students set up based on four processing skills]. Journal of Turkish Educational Sciences, 15(1), 1-25.

*Test, D. W., \& Ellis, M. F. (2005). The effects of LAP fractions on addition and subtraction of fractions with students with mild disabilities. Education and Treatment of Children, 28(1), 11-24. 
Tufan, S., \& Aykut, Ç. (2018). Şemaya dayalı strateji ve kendini izleme stratejisi öğretiminin hafif düzeyde zihinsel engelli öğrencilerin sözel matematik problemi çözme performanslarına etkisi [The effect of schema based strategy and self-monitoring on problem solving performance of students with mild intellectual disability]. Illköğretim Online, 17(2), 613-641. https://doi.org/10.17051/ilkonline.2018.419005

Tuncer, A. T. (2009). Şemaya dayalı sözlü matematik problemi çözme stratejisinin görme yetersizliği olan öğrencilerin sözlü problem çözme performanslarına etkisi [The effects of schema based word problem solving strategy on problem solving performance of students with visual impairment]. Eğitim ve Bilim, 34(153), 183-197.

*Van Garderen, D. (2007). Teaching students with LD to use diagrams to solve mathematical word problems. Journal of Learning Disabilities, 40(6), 540-553. https://doi.org/10.1177/00222194070400060501

Wildmon, M. E., Skinner, C. H., Watson, T. S., \& Garrett, L. S. (2004). Enhancing assignment perceptions in students with mathematics learning disabilities by including more work: An extension of interspersal research. School Psychology Quarterly, 19(2), 106-120. https://doi.org/10.1521/scpq.19.2.106.33310

Witzel, B. S. (2005). Using CRA to teach algebra to students with math difficulties in inclusive settings. Learning Disabilities: A Contemporary Journal, 3(2), 49-60.

Witzel, B. S., Mercer, C. D., \& Miller, M. D. (2003). Teaching algebra to students with learning difficulties: An investigation of an explicit instruction model. Learning Disabilities Research \& Practice, 18(2), 121131. https://doi.org/10.1111/1540-5826.00068

Xin, Y. P. (2008). The effect of schema-based instruction in solving mathematics word problems: An emphasis on prealgebraic conceptualization of multiplicative relations. Journal for Research in Mathematics Education, 39(5), 526-551. 


\section{Ankara University Faculty of Educational Sciences Journal of Special Education}

2022, 23(1), 191-218

\section{REVIEW}

Recieved Date: 27.07.20

Accepted Date: 27.01.21

OnlineFirst: 19.02 .21

\title{
Math Problem Solving Interventions for Middle School Students with Learning Disabilities: A Comprehensive Literature Review
}

\author{
Ufuk Özkubat ${ }^{1}$
}

\author{
Alpaslan Karabulut $\left.{ }^{(D)}\right)_{2}$
}

\author{
Cihan Sert $\left.{ }^{(}\right)_{3}$
}

\begin{abstract}
Introduction: Examining the research on math problem solving interventions for students with learning disabilities is important for identifying the interventions that will support these students. Assessing intervention studies in terms of certain quality standards provides information about the replication of applications and the reliability of the results. This study aimed to review math problem solving interventions for middle school students with learning disabilities in the last 20 years, list the characteristics of the studies descriptively, and examine them in terms of quality indicators.
\end{abstract}

Method: Based on the inclusion and exclusion criteria, nine articles were selected. They were investigated in the context of descriptive analysis and quality indicators. The studies were analysed descriptively. Their characteristics were identified. The studies were examined, and their quality levels were determined based on the quality indicators specified for the research using single-subject experimental designs.

Findings: Direct instruction, concrete-semi-concrete-abstract strategy, schema-based strategy, self-regulation strategies and hint cards, STAR strategy, open expression method, LAP strategy, visual strategies, Solve It!, and the SOLVE strategy were used for teaching problem solving skills as target skills. The general findings related to quality indicators showed that all studies met the specified criteria regarding the baseline level of basic quality indicators, experimental control/internal validity and external validity. Considering other components, it was observed that the study ranging from $44 \%$ to $78 \%$ met the specified criteria. Only one study was met all quality indicator items.

Discussion: The findings were discussed and suggestions were provided for teachers and researchers. Accordingly, it will be useful for experts working with students with learning disabilities to create intervention programs that include strategies to facilitate students' problem solving successfully, such as problem solving stages, schematic modifiers, cognitive and metacognitive strategies, and think-aloud protocols.

Keywords: Learning disabilities, math problem solving interventions, math education, descriptive analysis, quality indicators.

To cite: Özkubat, U., Karabulut, A., \& Sert, C. (2022). Math problem solving interventions for middle school students with learning disabilities: A comprehensive literature review. Ankara University Faculty of Educational Sciences Journal of Special Education, 23(1), 191-218. https://doi.org/10.21565/ozelegitimdergisi.774650

\footnotetext{
${ }^{1}$ Corresponding Author: Res. Assist. Dr., Gazi University, E-mail: ufukozkubat@gazi.edu.tr, https://orcid.org/0000-00029626-5112

${ }^{2}$ Assist. Prof., Bolu Abant Izzet Baysal Univesity, E-mail: karabulut_a@ibu.edu.tr, https://orcid.org/0000-0002-7355-5109

${ }^{3}$ Res. Assist., Gazi University, E-mail: cihan.sert@gazi.edu.tr, https://orcid.org/0000-0002-5602-1156
} 


\section{Introduction}

To equip students with basic academic skills, education starts from pre-school period. Acquiring basic academic skills is a must for students to be successful and live independently. Reading, writing, basic operations, and problem solving are the primary academic skills that students should acquire. Problem solving is one of the main intervention areas (Miller \& Mercer, 1997; Montegue, 1992). Math problem solving is a difficult skill for both students with learning disabilities and students with typical development (Jonassen, 2003; Schurter, 2002). Therefore, students who have difficulty in solving a problem should be supported (Hutchinson, 1993). There are different intervention methods to support students with learning disabilities (Lee et al., 2020; Maccini \& Hughes, 1997; Maccini et al., 2007; Marita \& Hord, 2017; Myers, et al., 2015). It is important to know the intervention methods and examine studies on intervention for choosing the appropriate method in line with student needs.

Various interventions are used to improve the performance of middle school students with learning disabilities (Lee et al., 2020; Maccini \& Hughes, 1997; Maccini et al., 2007; Marita \& Hord, 2017; Myers et al., 2015). These interventions generally appear as direct teaching methods, open expression methods, concrete-semiconcrete-abstract strategy, schema-based strategy, self-regulation strategies, and strategies presented through reminders. These methods and strategies play an important role in ensuring that the problem is identified and understood, determining the procedures to be chosen for the solution of the problem, realizing the solution by using the information given in the problem, making the necessary calculations correctly, tracking the order of solution steps, providing fluency, recalling information, and remembering the solution stages of the problem. Therefore, teaching students problem solving methods and strategies provides many opportunities and increases the accuracy of the results (Bottge \& Cho, 2013; Bottge et al., 2014; Hunt \& Vazquez, 2014; Scheuermann et al., 2009; Strickland \& Maccini, 2013).

It is important to evaluate both the quality level of practice in single-subject studies and the appropriateness of the procedures that need to be done methodologically. Objective criteria should be determined to make this assessment. Items that show high-quality research are called quality indicators (Cook et al., 2019). The literature abounds in studies conducted to measure the methodological suitability of single-subject studies (Busk \& Serlin, 1992; Kratochwill \& Stoiber, 2002). Horner et al. (2005) identified seven quality indicators that should be addressed to determine whether a single-subject study methodologically meets 'acceptable' criteria to be considered reliable. These are participants and settings, the dependent variable, the independent variable, baseline, experimental control/internal validity, external validity, and social validity (Horner et al., 2005). Determining the quality indicators of a study is also important for understanding to what extent the applied intervention causes a significant change over the dependent variable (Tankersley et al., 2008). A high-quality research prevents different inferences about the results of the related research and provides a clear view of the effect of the independent variable. As the quality level of a study is higher, researchers and readers have more confidence in the findings of the study (Odom et al., 2005).

Since the last quarter-century, there has been a limited number of studies examining the math interventions for middle school students with learning disabilities (Maccini \& Hughes, 1997; Maccini et al., 2007; Marita \& Hord, 2017; Myers et al., 2015). Three of these studies (Maccini \& Hughes, 1997; Maccini et al., 2007; Myers et al., 2015) intended to expand and update the literature. Accordingly, firstly, Maccini and Hughes (1997) examined 43 studies conducted between 1988 and 2007, Maccini et al. (2007) 23 between 1995-2006, Myers et al. (2015) 15 between 2006 and 2014, and Marita and Hord (2017) 12 between 2006 and 2014. Researchers advocate that it is important to deal with mathematics interventions for students with learning difficulties together (Lee et al., 2020). Although the primary aim of the abovementioned studies was to examine the math problem solving interventions for middle school students with learning disabilities, these studies are criticized for including fewer students with learning disabilities (Lee et al., 2020). For example, $34.1 \%$ of the sample were students with learning disabilities in Maccini, et al. (2007). This was 25.2 in Myers et al. (2015) and 18.2 in Marita and Hord (2017). The other participants were generally primary and high school students with severe emotional and behavioural disorders. Another limitation is that their findings were not presented separately regarding students with learning disabilities (Lee et al., 2020). Thus, in this study, the criteria for selecting the articles were determined based on the limitations of the previous studies.

There is a dearth of studies examining the effects of the intervention programs in special education in Turkey (Baki, 2014; Karabulut \& Özmen, 2018; Karabulut et al., 2015; Karakoç, 2002; Kot \&Yıłısş, 2018; Tuncer 2009; Tufan \& Aykut, 2018). These studies investigated intellectual disability, autism spectrum disorder, and students with visual impairments. Although studies were conducted to determine the cognitive and 
metacognitive strategies used by students with learning disabilities in solving mathematical problems (Özkubat, 2019; Özkubat \& Özmen, 2018), no study has investigated the effects of any intervention program aimed at increasing the problem solving performance of these students. In other words, the effect of intervention programs for different types of disabilities (e.g., mental impairment, visual impairment, autism) in the national literature was examined. Only the cognitive and metacognitive strategies used by students with learning disabilities during math problem solving were determined for these students. There is no study investigating the effects of math interventions on students with learning disabilities. Therefore, it is necessary to examine the math interventions for students with learning disabilities. In Turkey, there are two studies on teaching math skills in which quality indicators were examined (Aydın \& Tekin-İftar, 2019; Aydın et al., 2019) and a single-subject study conducted with individuals with multiple disabilities (Eldeniz-Çetin et al., 2019). The quality indicators determined by Horner et al. (2005) for single-subject studies were evaluated as "yes/no" in those studies. However, in the current research, a more detailed evaluation was made by using the triple Likert type scoring system by Jitendra et al. (2013). In this context, it is considered that the revealing the current practices by analysing math interventions for students with learning disabilities descriptively will be guiding. Thus, it will be possible to use the determined practices in the education of students with learning disabilities. Besides, the evaluation of the interventions examined in this study in terms of quality indicators is important in terms of giving methodological ideas to future studies. Thus, it will be possible to plan research for students with learning disabilities, develop appropriate intervention programs, and use evidence-based practices in Turkey. From this point of view, this study aimed to a) review math problem solving interventions for middle school students with learning disabilities in the last 20 years, b) list the characteristics of the related studies descriptively, and c) to examine them in terms of quality indicators.

\section{Method}

This research examined articles published in peer-reviewed journals between 2000-2020, including math problem solving interventions conducted with middle school students with learning disabilities. This section involves the inclusion and exclusion criteria, literature review, coding of the articles, descriptive analysis process, analysis process for quality indicators, and intercoder reliability.

\section{Inclusion and Exclusion Criteria}

The criteria for inclusion of the articles are as follows: a) articles published between 2000-2020, b) study group consisting of middle school students with learning disabilities, c) involving math problem solving intervention as an independent variable, d) using a single-subject experimental design, and e) being published in a refereed journal. The criteria for exclusion of the articles are as follows: a) not defining students with learning disabilities clearly, and the same student with other deficiencies (e.g., emotional and behavioural disorders, attention deficit and hyperactivity), b) including a sample with no or less middle school students, and c) not presenting the findings of students with learning disabilities separately after the intervention strategies.

\section{Literature Review}

Four steps (identifying, reviewing, suitability, inclusion) were followed to determine the articles. In the first step, ULAKBİM national databases (UVT), EBSCOhost, Education Research Complete, Education Resources Information Center (ERIC), Web of Science, Psychological Abstracts Index (PsycINFO), Google and Google Scholar search engines were utilized. The keywords were in both Turkish and English, which were learning disability, problem solving, math intervention, math program, math instruction, math performance, math academic achievement, middle school, grade 6, grade 7, grade 8, fractions, computation, algebra, geometry, and arithmetic. Accordingly, 142 studies were identified. In the second step, their titles, summaries and keywords were examined, and 100 studies remained after excluding the sources such as book chapter, report, descriptive and meta-analysis. Besides, the articles published in Exceptional Children, Learning Disabilities Quarterly, Journal of Learning Disabilities, Learning Disabilities Research \& Practice, Remedial \& Special Education and Journal of Special Education frequently focusing on problem solving interventions for students with special needs were searched. As a result, two more studies were identified. In the third step, 40 articles on math problem solving interventions conducted with students with learning disabilities were examined. However, 31 of these articles were excluded because they did not meet the grade level variable and not adopt a single-subject design. In the fourth step, nine studies that met the inclusion criteria were included in the review. The reviewed articles were indicated with the $\operatorname{sign}\left({ }^{*}\right)$ in the reference list. 


\section{Coding of the Articles}

The articles were selected considering the basic criteria for inclusion of the articles. First of all, a form was prepared based on the basic inclusion criteria. The researchers read and examined all of the articles in detail and recorded them in the prepared form.

\section{Descriptive Analysis Process}

The researchers examined the articles with the research review form that included a) the number of participants, b) grade and age level, c) gender, d) target skills, e) problem type, f) research design, g) setting, h) generalization and maintenance, i) reliability, j) social validity, and k) findings.

\section{Descriptive Analysis Process}

The Quality Indicators Analysis Form is an informal tool developed by Jitendra et al. (2013) used to determine the quality of a single-subject study based on the quality indicators of Horner et al. (2005). The form consists of 7 sections and 21 items: participants and settings ( 3 items), the dependent variable (5 items), the independent variable ( 3 items), baseline ( 2 items), internal validity ( 3 items), external validity ( 1 item), and social validity (4 items). They made necessary adaptations by using the quality indicators of Horner et al. (2005) as well as the statements of Jitendra et al. (2001) about math interventions. They adapted "yes/no" evaluation system of Horner et al. (2005) into a scoring system as 1, 2, and 3. The form has a 3-point Likert type: 3 refers to meeting the indicator, 2 refers to partially meeting the indicator, and 1 refers to not meeting the indicator. The total score obtained from the form varies between 21 and 63. For research to be evaluated as high quality in terms of meeting the quality indicators, a) each of the seven basic quality indicators should receive two points or more, b) each item should receive at least one point (Jitendra et al., 2013).

Prior to this research, the Quality Indicators Analysis Form was translated into Turkish. Regarding translation, the opinion of a linguist was asked. After the revisions, the Turkish form was sent to two experts in the field of special education, and their opinions were asked. Expert opinion form was prepared as 5-point Likert type, 'absolutely appropriate' $=5$, 'appropriate' $=4$, 'neutral' $=3$, 'not appropriate' $=2$, 'strongly not appropriate' $=1$. In the expert opinion form, the quality indicators were checked in terms of clarity, comprehensibility, and coverage. The items received at least 4 points or more from both experts. The corrections were made if necessary.

\section{Intercoder Reliability}

Reliability was calculated by using the formula "Consensus / (Consensus + Cisagreement) X 100" (House, House \& Campbell, 1981).

\section{Findings}

\section{Descriptive Analysis Findings}

\section{Participants}

The study group consisted of 45 students with learning disabilities. Participants were $34(76 \%)$ males and $11(26 \%)$ females. Twenty-four (54\%) were between 11-13 years and $15(33 \%)$ between $14-16$. As to the grade level, $12(27 \%)$ students were in $6^{\text {th }}$ grade, $7(13 \%)$ in $7^{\text {th }}$ grade, and the majority in $8^{\text {th }}$ grade. The age of six $(13 \%)$ participants and the grade level of three $(6 \%)$ were not identified.

\section{Descriptive Information of the Study}

The articles were examined in terms of target skill, problem types, research design and setting. Regarding the research designs, four studies (44\%) adopted multiple baseline design and five studies (56\%) used multiple probe design. $44 \%(n=4)$ of the studies were carried out in the special education class and the support education class and $33 \%(n=3)$ was conducted in a classroom in the school. Besides, in one study $(11 \%)$ it was stated that the intervention was implemented in the general education class. Direct instruction, concrete-semi-concreteabstract strategy, schema-based strategy, self-regulation strategies and hint cards, STAR strategy, open expression method, LAP strategy, visual strategies, Solve It!, and the SOLVE strategy were used for teaching problem solving skills as target skills. The aforementioned studies focused on circumference and area, percentage and ratio, change, fraction, four operations, and single unknown equation problem types. 


\section{Research Findings}

The findings related to the participants were studied according to variables such as a) generalization and monitoring, b) inter-coder reliability and application reliability, and c) social validity. The visual graphics and written findings of the nine studies showed that various problem solving teaching interventions were effective in teaching target skills. Regarding the graphics of the single-subject experimental designs in which problem solving interventions were examined, the curves at the baseline had an increased slope during the intervention phases.

\section{Findings Related to Quality Indicators}

The study presents information related to a) participants and setting, b) dependent variable, c) independent variable, baseline, d) experimental control/internal validity, e) external validity and f) social validity.

The general findings showed that all studies met the specified criteria regarding the baseline level of basic quality indicators, experimental control/internal validity and external validity. Considering other components, it was observed that the study ranging from $44 \%(n=4)$ to $78 \%(n=7)$ met the specified criteria. Only one study was met all quality indicator items (Jitendra et al., 2002).

\section{Findings Related to Intercoder Reliability}

Intercoder reliability was $95 \%$ for the descriptive analysis process. For this process reliability was minimum $89 \%$ and maximum $100 \%$. Intercoder reliability was $94 \%$ for the descriptive analysis process. For this process reliability was minimum $82 \%$ and maximum $100 \%$.

\section{Discussion}

This study aimed to determine math problem solving interventions for middle school students with learning disabilities between 2000-2020 and to provide information for further studies and practitioners by examining the articles in terms of the quality indicators. Three main results can be emphasized. First, various teaching interventions were for students with learning disabilities and had positive results. Second, the strategies used in the interventions improved the problem solving performance of students with learning disabilities. Finally, most of the studies met some components of the basic quality indicators. More studies that meet the quality indicators are needed for an evidence-based practice to emerge. Thus, it is necessary to conduct more studies to support problem solving performances of students with learning disabilities. In this section, findings related to descriptive analysis and quality indicators were discussed under separate headings.

\section{Discussing Findings Related to Descriptive Analysis}

Strategies such as STAR (Maccini \& Ruhl, 2000), SOLVE (Freeman-Green et al., 2015), and LAP (Test $\&$ Ellis, 2005) were used. These strategies are mnemonics and each letter in the strategy name refers to a cognitive strategy step.

The current study also utilized the concrete-semi-concrete-abstract approach (Hunt \& Vasquez, 2014), which was used to support the problem solving skills of students with learning disabilities. Students with learning disabilities should be provided to identify quantities through problems involving real objects and should be provided to show the relationships between these quantities in graphs, tables, charts, figures, and formulas. In other words, for effective problem solving, students cannot learn by observing. The student needs to participate both physically and mentally by interacting directly with the setting.

In this study, metacognitive strategies are considered to be one of the reasons for the effectiveness of the interventions on students' problem solving skills. Metacognitive strategies include self-observation, selfevaluation, self-control, self-monitoring, self-instruction, self-questioning. These strategies emerge especially in a new or difficult task and are useful in completing the task (Lucangeli \& Cabrele, 2006).

Another reason for the effectiveness of the interventions on students' problem solving skills is the visualization strategy (Jitendra et al., 2002; Van Garderen 2006). Literature supports these findings (Gersten et al., 2009; Ives, 2007).

Supportive and structured worksheets used in all of the studies were considered to be one of the variables that are effective in increasing students' problem solving performances (Cass et al., 2003; Freeman-Green et al., 2015; Hunt \& Vasquez, 2014; Jitendra et al., 2002; Joseph \& Hunter, 2001; Maccini \& Ruhl, 2000; Scheuermann et al., 2009; Test \& Ellis, 2005; Van Garderen, 2007). In this context, Marshall (1995) states that the promoters 
used in problem solving teaching facilitate the recognition of the situation in the problem and the selection of the appropriate operation while solving the problem.

\section{Discussing the Findings Related to Quality Indicators}

Only one study (Jitendra et al., 2002) met all seven quality indicators determined by Horner et al. (2005). Three studies provided acceptable evidence with six out of the seven indicators (Freeman-Green et al., 2015; Hunt \& Vasquez, 2014; Maccini \& Ruhl, 2000). Four studies provided acceptable evidence with five indicators (Cass et al., 2003; Scheuermann et al., 2009; Test \& Ellis, 2005; Van Garderen, 2007). The remaining study provided acceptable evidence with four indicators (Joseph \& Hunter, 2001). These findings are consistent with the ones reported by Aydın and Tekin-İftar (2019), Jitendra et al. (2001), and Jitendra et al. (2013).

This study have some limitations. It examined single-subject studies published in peer-reviewed journals. Publications such as group experimental studies, postgraduate theses, and research reports were excluded. The studies reached are limited to the results of the search engines determined in line with the inclusion criteria. Within the scope of this research, it is aimed to investigate the math problem solving interventions for students with learning disabilities. There are sub-types of learning disabilities such as mathematics, reading and writing difficulties. The interventions for these sub-types might differ. However, no sub-types of learning disability were examined since they were not specified in the studies investigated. Horner et al. determined the quality indicators for single-subject studies in 2005. The criteria for applying single-subject studies can be updated day by day. For example, at least three data points were expected to show stability to move from the baseline to the application level, some researchers currently do not consider the three data points as sufficient. Thus, assessment based on the quality indicators determined in 2005 can be considered as a limitation.

There are suggestions for instruction, practice, and further studies. The literature shows that students with learning disabilities succeed in math problem solving when supported by appropriate interventions. Accordingly, it will be useful for experts working with students with learning disabilities to create intervention programs that include strategies to facilitate students' problem solving successfully, such as problem solving stages, schematic modifiers, cognitive and metacognitive strategies, and think-aloud protocols. The finding of this research is expected to provide a basis for the studies in Turkish literature and to shed light on the intervention programs to be prepared. This is because no study has focused on any teaching methods or intervention strategies including approaches such as teaching cognitive and metacognitive strategies, use of schematic regulators, and problemoriented teaching in solving mathematical problems for middle school students with learning disabilities in Turkey.

\section{Author's Contributions}

The authors collaboratively performed the tasks of determining the subject of the manuscript, research design, data collection, data analysis and reporting of the study. 